\title{
Effect of dilution method on diesel exhaust particulate matter concentrations and size distributions
}

Karthikeyan C. Venkatasubramaniam

West Virginia University

Follow this and additional works at: https://researchrepository.wvu.edu/etd

\section{Recommended Citation}

Venkatasubramaniam, Karthikeyan C., "Effect of dilution method on diesel exhaust particulate matter concentrations and size distributions" (2007). Graduate Theses, Dissertations, and Problem Reports. 1815.

https://researchrepository.wvu.edu/etd/1815

This Thesis is protected by copyright and/or related rights. It has been brought to you by the The Research Repository @ WVU with permission from the rights-holder(s). You are free to use this Thesis in any way that is permitted by the copyright and related rights legislation that applies to your use. For other uses you must obtain permission from the rights-holder(s) directly, unless additional rights are indicated by a Creative Commons license in the record and/ or on the work itself. This Thesis has been accepted for inclusion in WVU Graduate Theses, Dissertations, and Problem Reports collection by an authorized administrator of The Research Repository @ WVU. For more information, please contact researchrepository@mail.wvu.edu. 
Effect of Dilution Method on Diesel Exhaust Particulate Matter Concentrations and Size Distributions

Karthikeyan C. Venkatasubramaniam

Thesis submitted to the College of Engineering and Mineral Resources

at West Virginia University in partial fulfillment of the requirements

for the degree of

Master of Science
in
Mechanical Engineering

Mridul Gautam, Ph.D., chair

W. Scott Wayne, Ph.D.

Benjamin C. Shade, Ph.D.

Department of Mechanical and Aerospace Engineering

Morgantown, West Virginia

2007

Keywords: Hot Dilution, Cold Dilution, Dilution Ratio, Oxidation catalyst 


\section{ABSTRACT \\ Effect of Dilution Method on Diesel Particulate Matter Concentrations and Size Distributions}

\section{Karthikeyan C. Venkatasubramaniam}

The objective of this study was to evaluate the effect of different dilution methodologies on diesel exhaust particle size distributions and concentrations. A two-stage ejector based dilution system was used to dilute the raw exhaust at total dilution ratios of 240 and 504. A naturally aspirated, mechanically controlled, 3-cylinder inline, 0.953 liter Daihatsu Model DM950DTH engine was employed and tests were conducted with and without a wire mesh Diesel Oxidation Catalyst (DOC). Federal Diesel \#2 with a sulfur content of 350 ppm was used as the testing fuel. The first dilution method (hot dilution) comprised of hot air dilution in stage 1 and cold air dilution in stage 2. The second method (cold dilution) comprised of cold air dilution in both the stages. A Scanning Mobility Particle Sizer (SMPS), Model 3936 was used for measuring the particle size distributions and concentrations. The engine was operated at four steady state set points, which were selected for a mix of both the volatile and solid particulate matter (PM) fractions in the exhaust stream. At a dilution ratio of 240, the influence of the volatile fraction on the PM size distribution and concentration was comparatively lower in the hot dilution method than the cold dilution method. The cold dilution method resulted in a count median diameter (CMD) of $44.5 \mathrm{~nm}$ compared to $53.3 \mathrm{~nm}$ with the hot dilution method when the engine was operating at an intermediate speed and 50\% load. A similar trend was observed for the remaining engine set points. The effect of dilution method on PM size distribution and concentrations was not noticeable for a dilution ratio of 504, which indicated that very high dilution ratios have minimal impact. PM concentrations downstream of the DOC showed a reduction in the concentration of nuclei and accumulation mode particles for both the dilution methods. This is possibly indicating the oxidation of PM in the oxidation catalyst. 


\section{ACKNOWLEDGEMENTS}

It has been quite a long and hard journey for me so far (aahhhh, who am I kidding?). Life has been good and fun for me for the better part and my family and friends have been responsible for this. I am hoping that I have included everyone who has made a difference to me.

This is a point in my career where I have to thank my family for what I am today, for the education they gave, for all the support and freedom they gave me to choose what I wanted to be. Amma, Appa, Kumar and Krithika, thanks for being there for me when I needed you all the most.

I thank Dr. Gautam for giving me the opportunity to be his graduate student and making me feel comfortable to work with him. Dr.Gautam, I thank you for being a guide and a friend and for all the help you have extended to complete my thesis and choose a career path for myself.

I thank my committee members for evaluating my thesis report and I appreciate your time and effort to help me make it a good one.

Dan Carder, according to me, the guy who knows it all and has the patience to teach you that. He has been a wonderful and a very comfortable person to work with. Thanks for all your help Dan, so much that I cannot even start counting the innumerous times I have pestered you. I hope I can get to half as what you are, someday!!!

Tom Spencer, I surely appreciate all your help with whatever I needed in ERC. And thanks for all the fun moments to make working more enjoyable. I will always be grateful to you. 
This is the toughest part, to talk about friends. Guys, you are making it so difficult for me and I hope that I have not missed any of you out of this because you have all made a big difference in one way or other and I am glad we crossed paths at some point.

Shashi, my good friend and ever-sleeping roomie. I thank you for all the tutoring at ERC and I owe half of my knowledge about testing to you. Thanks buddy!!

Mohan and Sam, I thank you both for your help whenever I needed it. I will always remember the Wings nights at Keglers, Crocketts and BW3.

Arvind, I thank you for all the help with my thesis testing. I hope you treasure the beer bottle collection we have and build on it. I wish I could stay on to help you with that, but I know you will make it. I wish you good luck with your $\mathrm{PhD}$.

All work and no play would have certainly made me a dull and boring guy. Arvind, Abishek \& Sukanya, I thank you all for being the wonderful you have been and for all the fun times we have had everyday. I am definitely going to miss you all!!

Praveen, DJ and Amar, thank you for making me feel comfortable in Morgantown when I was new to this place. I would not have liked it if not for you guys around.

This is going to be the last but I have reserved it for that special person in my life, who has been extremely supportive even though we have been miles away. Sarita, I have always enjoyed those long telephone conversations (even though I felt a pinch in my pocket!!!) and you have been my strength and drive since the time I have known you. I thank you for being so understanding and look forward to our life together ahead.

And now let us get down to business!!! 


\section{NOMENCLATURE}

AIM

CARB

CMD

CPC

DOC

DMA

DPF

DPM

EC

EERL

$\mathrm{H}_{2} \mathrm{SO}_{4}$

PM

Scfm

SOF

SMPS

USEPA
Aerosol Instrument Manager

California Air Resources Board

Count Median Diameter

Condensation Particle Counter

Diesel Oxidation Catalyst

Differential Mobility Analyzer

Diesel Particulate Filter

Diesel Particulate Matter

Electrostatic Classifier

Engine and Emissions Research Laboratory

Sulfuric Acid

Particulate Matter

Standard Cubic Feet per Minute

Soluble Organic Fraction

Scanning Mobility Particle Sizer

United States Environmental Protection Agency 


\section{TABLE OF CONTENTS}

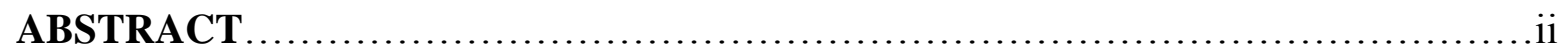

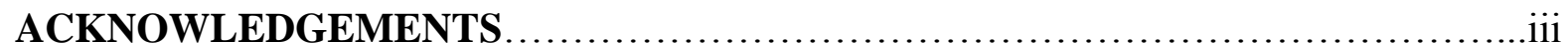

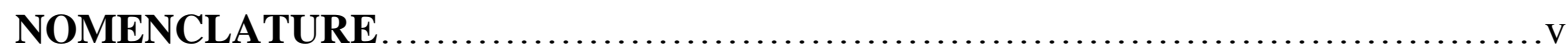

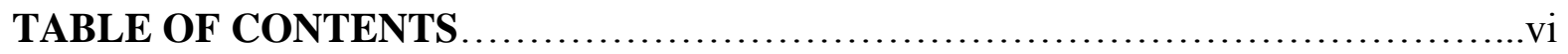

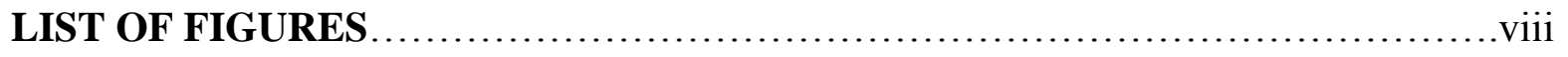

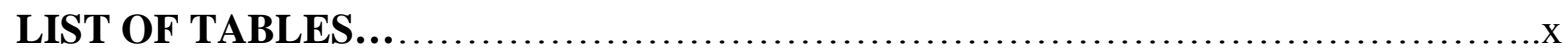

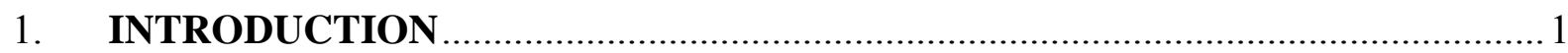

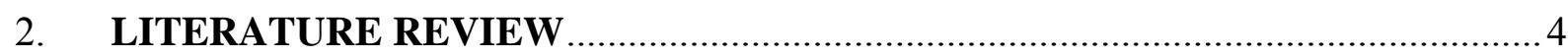

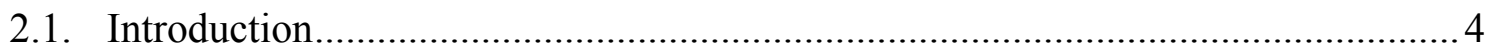

2.2. Health Effects of Particulate Matter .................................................................. 4

2.3. Diesel Engine Particulate Matter ..................................................................... 5

2.4. Composition of Diesel Engine Particulate Matter ..................................................5

2.5. Factors Influencing Measurement of PM Size Distribution and Concentrations ....7

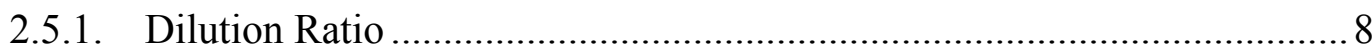

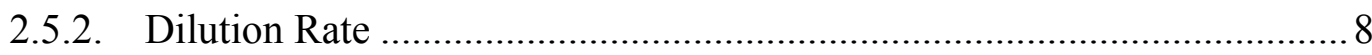

2.5.3. Dilution Air Temperature ………………….....................................

2.6. Separation of Solid and Volatile Fraction..............................................................

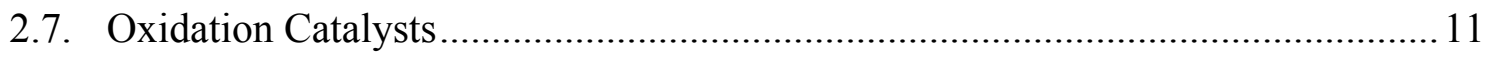

3. EXPERIMENTAL SETUP AND TESTING PROCEDURE ……........................ 12

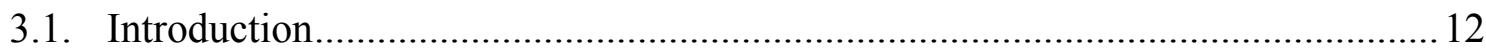

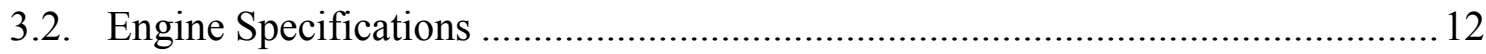

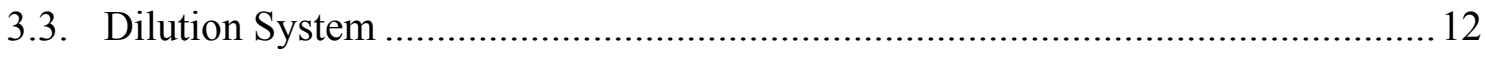

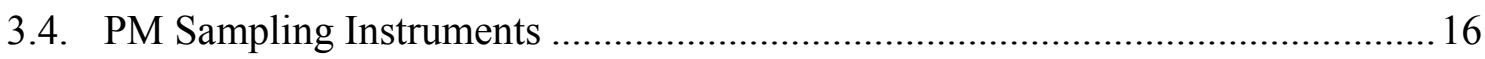

3.4.1. Scanning Mobility Particle Sizer (SMPS) …………………………....... 17

3.4.2. Model 3480 Electrospray Aerosol Generator...........................................21

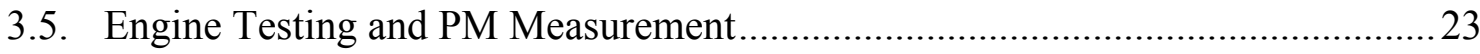




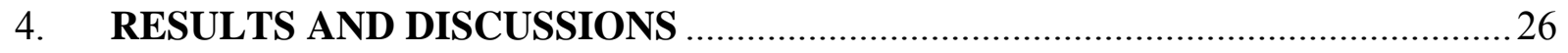

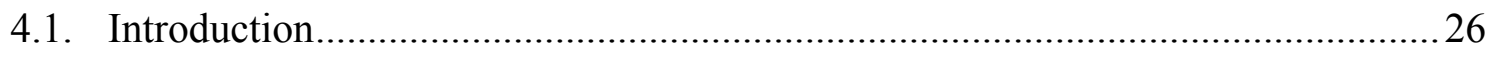

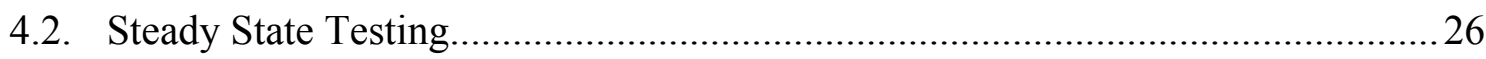

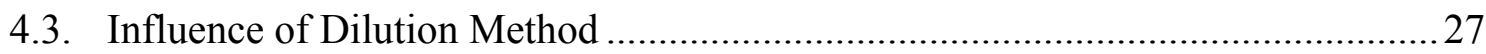

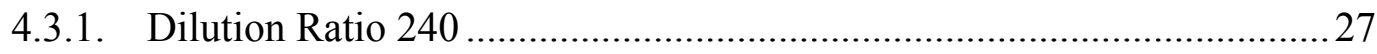

4.3.2. Dilution Ratio 504 ............................................................................ 31

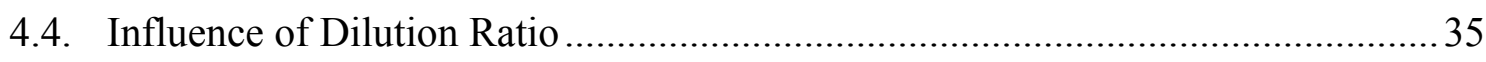

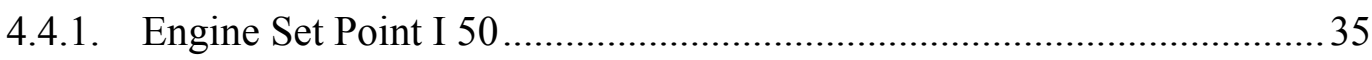

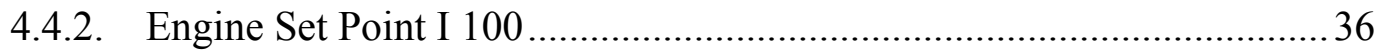

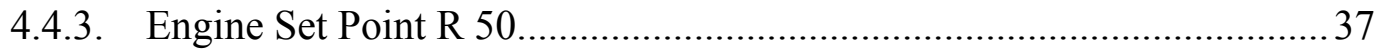

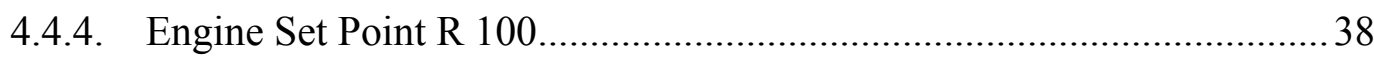

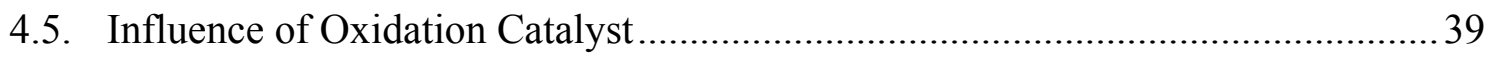

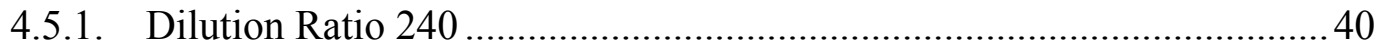

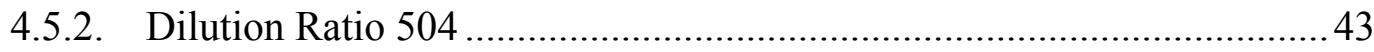

5. CONCLUSIONS AND RECOMMENDATIONS ............................................ 47

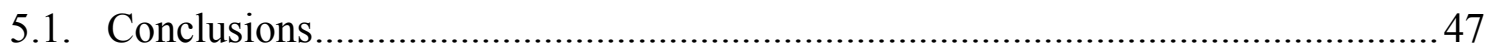

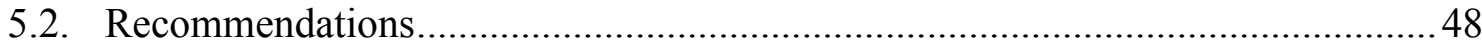

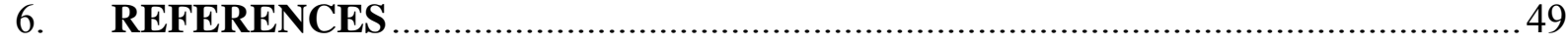

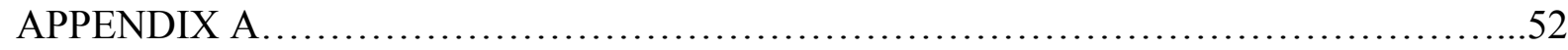

APPENDIX B ................................................................ 53

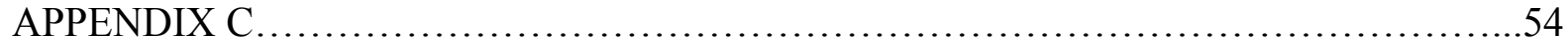




\section{LIST OF FIGURES}

Figure 2-1. Simplified schematic mechanism of the condensation and nucleation process during diesel exhaust dilution and cooling. Blue: Volatile $\left(\mathrm{H}_{2} \mathrm{SO}_{4}\right)$; Red: Semi-volatile organics (unburned fuel); Green: Low-volatile organics (lube oil) [2].

Figure 2-2. Typical engine exhaust mass and number weighted size distributions shown with

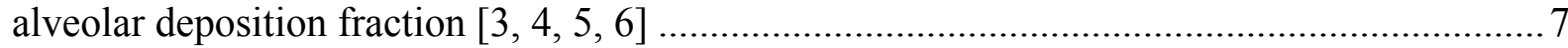

Figure 3-1. Working principle of an Ejector Diluter [23] ............................................... 13

Figure 3-2. DR comparison cold dilution method after thermodesorber at $300{ }^{\circ} \mathrm{C}$ and hot

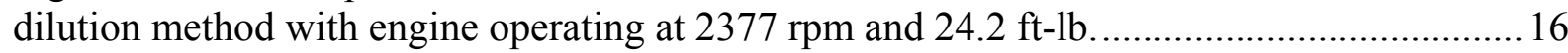

Figure 3-3. SMPS 3936 (Model 3080 Classifier and Model 3025 A CPC) by TSI Inc [24] ... 17

Figure 3-4. Electrostatic Classifier fitted with impactor at inlet [24] ................................ 18

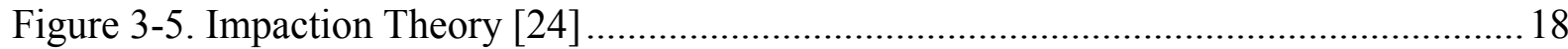

Figure 3-6. Schematic of TSI Inc Model 3480 Electrostatic Classifier with Nano-DMA [24] 20

Figure 3-7. Schematic of TSI Inc Model 3025 A Condensation Particle Counter [27] .......... 21

Figure 3-8. TSI Inc. Model 3480 Electrospray Aerosol Generator [25] .............................. 22

Figure 3-9. Schematic of TSI Inc Model 3480 Electrospray Aerosol Generator [25] ............ 23

Figure 3-10. Schematic of Experimental Setup..............................................................25

Figure 4-1. Particle Size Distribution at I 50 engine set point, DR 240, Cold Vs Hot Dilution Method ......................................................................................... 28

Figure 4-2. Particle Size Distribution at I 100 engine set point, DR 240, Cold Vs Hot Dilution Method....

Figure 4-3. Particle Size Distribution at R 50 engine set point, DR 240, Cold Vs Hot Dilution Method 30

Figure 4-4. Particle Size Distribution at R 100 engine set point, DR 240, Cold Vs Hot Dilution Method 31

Figure 4-5. Particle Size Distribution at I 50 engine set point, DR 504, Cold Vs Hot Dilution Method 32

Figure 4-6. Particle Size Distribution at I 100 engine set point, DR 504, Cold Vs Hot Dilution Method....

Figure 4-7. Particle Size Distribution at R 50 engine set point, DR 504, Cold Vs Hot Dilution Method

Figure 4-8. Particle Size Distribution at R 100 engine set point, DR 504, Cold Vs Hot Dilution Method 
Figure 4-9. Particle Size Distribution at I 50 engine set point, Cold Dilution Method,

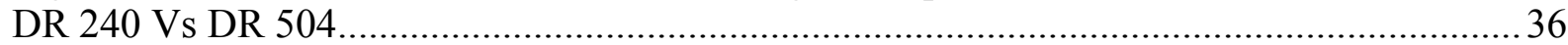

Figure 4-10. Particle Size Distribution at I 100 engine set point, Cold Dilution Method, DR 240 Vs DR 504

Figure 4-11. Particle Size Distribution at R 50 engine set point, Cold Dilution Method, DR 240 Vs DR 504.

Figure 4-12. Particle Size Distribution at R 100 engine set point, Cold Dilution Method, DR 240 Vs DR 504. 39

Figure 4-13. Particle Size Distribution at I 50 engine set point, Cold \& Hot Dilution Method, DR 240, Before and After Oxidation Catalyst 41

Figure 4-14. Particle Size Distribution at I 100 engine set point, Cold \& Hot Dilution Method, DR 240, Before and After Oxidation Catalyst 42

Figure 4-15. Particle Size Distribution at R 50 engine set point, Cold \& Hot Dilution Method, DR 240, Before and After Oxidation Catalyst .42

Figure 4-16. Particle Size Distribution at R 100 engine set point, Cold \& Hot Dilution Method, DR 240, Before and After Oxidation Catalyst 43

Figure 4-17. Particle Size Distribution at I 50 engine set point, Cold \& Hot Dilution Method, DR 504, Before and After Oxidation Catalyst ..... 44

Figure 4-18. Particle Size Distribution at I 100 engine set point, Cold \& Hot Dilution Method, DR 504, Before and After Oxidation Catalyst 44

Figure 4-19. Particle Size Distribution at R 50 engine set point, Cold \& Hot Dilution Method, DR 504, Before and After Oxidation Catalyst 45

Figure 4-20. Particle Size Distribution at R 100 engine set point, Cold \& Hot Dilution Method, DR 504, Before and After Oxidation Catalyst 45 


\section{LIST OF TABLES}

Table 3-1. Dilution Ratios for Two Stage Mini-Dilution Tunnel ......................................... 14

Table 3-2. Engine Steady State Set Points .......................................................................... 25

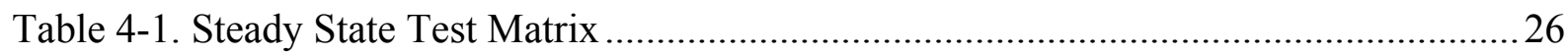




\section{INTRODUCTION}

Mass emissions of particulate matter (PM) from diesel engines have been regulated by the United States Environmental Protection Agency (USEPA) and California Air Resources Board (CARB) due to their inherent toxic effects. Stringent regulations have been imposed from time to time reflected by $0.01 \mathrm{~g} / \mathrm{bhp}-\mathrm{hr}$ for 2007 against $0.6 \mathrm{~g} / \mathrm{bhp}-\mathrm{hr}$ in 1988 for heavy duty diesel engines. Changes in engine technology and retrofitting engines with diesel particulate traps have helped the engine manufacturers meet these emission demands. However, a reduced mass concentration does not directly imply a reduction in particulate matter number concentration as indicated by a few studies [1].

Diesel particulate matter (DPM) is a complex mixture of elemental carbon, hydrocarbons, sulfur compounds and other species. DPM can be broadly classified into solid particles and volatile fraction. Solid particles include elemental carbon and engine wear. The volatile fraction includes hydrocarbons and sulfur compounds. This classification is dependent on temperature, dilution, measurement techniques, sampling methodology and other parameters. The number concentration measurements made not only include particles formed during the combustion process, but also particles formed during transfer of exhaust for measurement, subsequent cooling and dilution conditions. Solid particles can further be classified into 3 modes-nuclei mode, accumulation mode and coarse mode. Nuclei mode mainly comprises of volatile organic material and sulfur compounds. Particles in this mode can either be solid particles or droplets and are up to 50nm in size. Since measurements in this mode are very sensitive to temperature, repeatability in PM size measurements could be challenging. Particles in the accumulation mode are typically in the size range of 50-300nm and include elemental carbon, ash and measurements are repeatable. Coarse mode includes re- 
entrained material in the engine exhaust line and is not repeatable. Particles in the nuclei mode can contribute to about $90 \%$ of the number but significantly less to the total mass [13].

Diesel Particulate Filters (DPFs) have reduced diesel exhaust by as much as 99\%, but have, in turn increased the number concentration in the nuclei mode [1, 22]. This can be attributed to the high operating temperatures inside the DPF's (close to engine exhaust temperature), sampling methodology and dilution conditions. The volatile fraction escapes the trap and subsequently forms particles in the nuclei mode range by homogeneous nucleation.

Health effects studies of PM have shown that solid particles in the ultra-fine mode can cause chronic lung diseases and have genotoxic and mutagenic effects [7, 8, 9]. These conclusions provide enough evidence and reason to treat the solid and volatile fraction of a diesel engine PM separately, either by eliminating the volatile fraction before measurement or by preventing nucleation. The volatile fraction can be avoided in the measurements by two techniques. One method is by using thermodesorbers, where the engine exhaust is heated to a specified temperature and then removing it by using an adsorber agent. The second method involves heating the exhaust to a temperature at which the volatile fraction evaporates, and subsequently diluting it to prevent supersaturation. This method ensures that the volatile fraction does not affect the particle measurement of an exhaust since the volatile fraction remains in the gas phase.

The objective of this thesis was to compare the influence of (i) two dilution methods cold air dilution and hot air dilution, (ii) high dilution ratios, and, (iii) an aftertreatment device (oxidation catalyst) on the diesel engine particulate matter size distributions and concentrations. A 2005 model, 0.954 liter, 3 cylinder (inline) Daihatsu diesel engine has been used in this study. The engine was operated on steady state modes with set points chosen to 
enable a study of both, the volatile and solid fractions of PM. The objective of this comparative exercise was to recommend an exhaust dilution method which will be most suitable for measuring PM concentrations and size distributions with an SMPS with minimal sampling artifacts. High dilution ratios, namely 240 and 504, were selected for this work, in order to study particle size distributions and concentrations which will be representative of real world or highway dilutions, or even dilution conditions in mines where dilution ratios have been observed to be high. All particle size and concentration measurements were made with an SMPS Model 3936 manufactured by TSI Inc. Subsequent chapters discuss work done prior to this and results and conclusions for this study. 


\section{LITERATURE REVIEW}

\subsection{Introduction}

Particulate matter (PM) emissions from diesel engines have been under continuous scrutiny by United States Environmental Protection Agency (USEPA) and California Air Resources Boar (CARB), and this is evident in the stringent regulations enforced year after year. But regulations so far have been mass based and studies have indicated that a decrease in PM mass has in turn reflected in an increase in number concentrations of PM, which are considered harmful to human health [9]. This initiated extensive research in the field of measuring diesel engine PM size distributions and number concentrations and development of accurately measurement technologies to control the same. The work done in this thesis is an attempt to compare two different exhaust dilution methods, which will enable accurate size distribution and concentration measurements, and examine the effect of dilution ratios and an oxidation catalyst on the PM size distribution. The following sections brief the reader on work done so far in this research area.

\subsection{Health Effects of Particulate Matter}

Epidemiological studies have shown a relationship between PM (from all sources including diesel engine) concentrations and death rates [7,8]. Recent research has linked environmental exposure to fine particles less than $2.5 \mu \mathrm{m}$ in size [PM2.5] to adverse health effects and suggests that particulate matter concentration might be a better indicator of the health effects involved rather than the mass PM2.5 or PM10 mass concentrations [9]. These hazardous effects of PM have kindled research in particulate matter number concentration and distribution of a diesel engine exhaust. Extensive research was and is currently being 
conducted in an attempt to measure and depict PM concentration and advocate changes to reduce the same.

\subsection{Diesel Engine Particulate Matter}

Air intake in a diesel cycle occurs during the intake stroke, and fuel is injected during the compression stroke. After a short ignition delay (of the order of milliseconds), fuel auto ignites resulting in combustion associated with a high rate of heat release. The controlled combustion phase starts after the premixed air-fuel mixture is completely consumed, during which the burning rate is controlled by the rate at which fuel is injected. Researchers say that most of the particles emitted by a diesel engine are formed during the process of controlled combustion since the particles formed during the uncontrolled combustion process are later oxidized in the combustion process [1].

\subsection{Composition of Diesel Engine Particulate Matter}

Particles are described by their size, number, surface, mass concentration and/or their chemical composition. Diesel exhaust particles mainly consist of agglomerates of carbon particles and a percentage of semi-volatile components, such as $\mathrm{H}_{2} \mathrm{SO}_{4}$ and organic species that might condense on the surface of the carbon particles or might even nucleate to form ultra-fine nanometer-sized particles during the dilution and cooling process [2]. Figure 2-1 shows the mechanism described. 


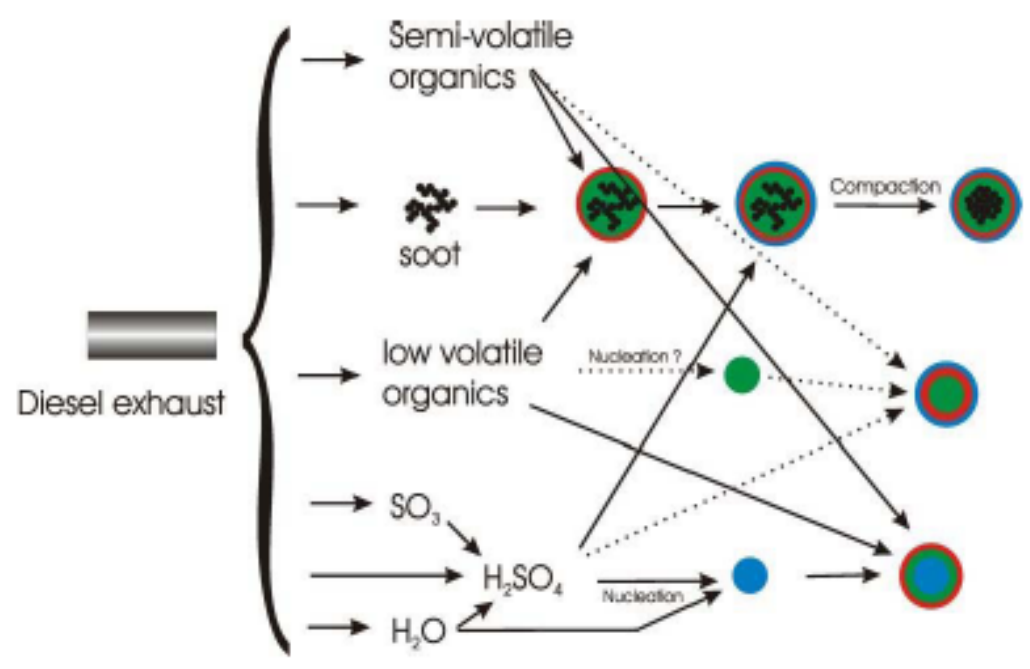

Figure 2-1. Simplified schematic mechanism of the condensation and nucleation process during diesel exhaust dilution and cooling. Blue: Volatile $\left(\mathrm{H}_{2} \mathrm{SO}_{4}\right)$; Red: Semi-volatile organics (unburned fuel); Green: Low-volatile organics (lube oil) [2]

Combustion aerosol is said to follow a lognormal, trimodal size distribution as shown in Figure 2-2. Both mass and number distributions are shown with the concentration in any size range being proportional to the area under the corresponding curve in that range. Figure 2-2 also provides information on size range definitions for atmospheric particles (PM10, PM2.5, ultra-fine particles and nanoparticles). Based on the size particles may be classified into 3 modes, namely nuclei mode, accumulation mode and coarse mode.

Nuclei mode particles are in the size range of 5-50nm, and consist of metallic ash, elemental carbon, and semi-volatile organic and sulfur compounds that form particles during dilution and cooling. Particles in the nuclei mode contribute to less than $20 \%$ of the total mass but more than $90 \%$ to the total particle concentration. The accumulation mode particles are in the size range of $50-1000 \mathrm{~nm}$, primarily consisting of carbonaceous agglomerates and adsorbed materials. Accumulation mode particles contribute between $60-70 \%$ to the total 
mass. The coarse mode includes all particles greater than $1000 \mathrm{~nm}$ in size, and contribution of this mode to the total mass is about $5-20 \%[3,4]$. Figure $2-2$ also gives relationships between idealized diesel particulate matter number and mass weighted size distributions and the alveolar deposition curve $[5,6]$.

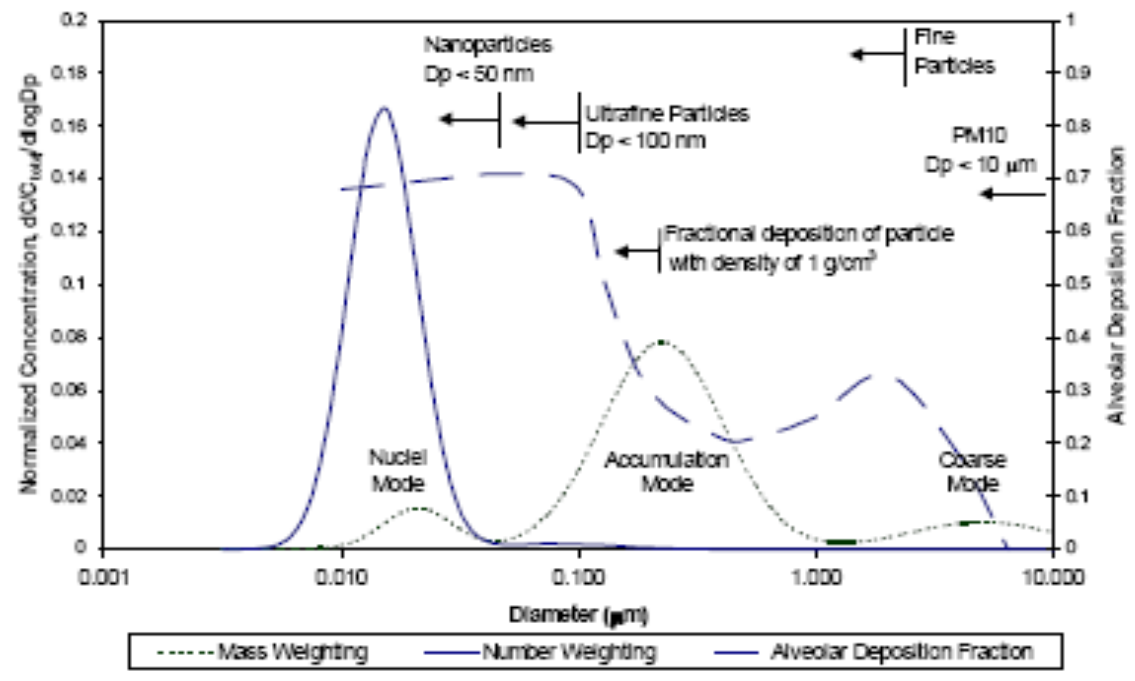

Figure 2-2. Typical engine exhaust mass and number weighted size distributions shown with alveolar deposition fraction $[3,4,5,6]$

\subsection{Factors Influencing Measurement of PM Size Distribution and Concentrations}

Published literature has indicated that a large number of factors affect the particle growth, and hence, measured particle concentrations and size distributions might not be a reflection of the way PM behaves in atmospheric conditions[10, 11, 12 13, 14]. These factors include, but not limited to, sampling systems, dilution method, dilution ratio, dilution temperature, residence time and transfer lines. This effort was limited to mainly studying the influence of dilution ratio, dilution method and an oxidation catalyst. 


\subsubsection{Dilution Ratio}

Experiments have consistently shown that the accumulation mode is largely unaffected by any change in dilution ratio. However, an increase in concentration of particles in the nuclei mode has been reported with decreasing dilution ratios and vice-versa [10]. It has also been observed that the number mean diameter of the particle size distributions decreased with increasing dilution ratios but the total number concentration particles did not change with change in dilution ratio [11]. Khalek et al. [14] reasoned that an increasing dilution ratio reduces the vapor phase concentration of all exhaust species in an isothermal process. This weakens both the nucleation of new particles as well as the driving force which aids it.

Based on this fact it can be confirmed that dilution ratio has a significant effect only on the nucleation of particles during dilution (to produce particles less than $50 \mathrm{~nm}$ in size), but not on accumulation mode particles.

\subsubsection{Dilution Rate}

Particles in the nuclei mode primarily consist of volatile and semi-volatile materials, and formation of particles is dependent on the saturation conditions which have an influence on the condensation or evaporation. Experiments suggest that a tendency to produce nuclei mode particles during dilution is maximized at an intermediate rate of dilution. If the dilution rate was faster than the characteristic times for adsorption, higher saturation ratios were produced which aided nucleation. The study concluded that the strongest driving force for condensation, adsorption and nucleation occurred at a dilution range of $5: 1$ to $50: 1$ [10]. These results agreed with the experimental results of Kittelson et al. [12]. 


\subsubsection{Dilution Air Temperature}

As discussed in the section above, nucleation of particles is dependent on the saturation ratio, which is in turn dependent on the temperature. So, a lesser dilution air temperature will result in a higher saturation ratio which will increase the nucleation rate. Studies performed as part of the CRC E-43 program, support this theory and results showed that a larger number of nanoparticles were formed during the dilution of engine exhaust in the atmosphere at an ambient temperature of $10{ }^{\circ} \mathrm{C}$ than at $20^{\circ} \mathrm{C}$. Quang Wei et al. [13] conducted experiments with a 1995 model Perkins T 4.40 diesel engine. A single stage dilution tunnel was used to dilute the raw engine exhaust and results indicated formation of larger concentrations of nuclei mode particles at lower dilution air temperatures. The accumulation mode remained unaffected by the dilution air temperature. This result was profound for fuels with higher sulfur content and agreed with results produced by Khalek et al. [14]. Particle number concentration measurements were made on a 1995 turbocharged, direct injection, medium duty diesel engine by Khalek et al. [14], to study the influence of dilution conditions (dilution temperature, residence time and dilution ratio). Conclusions drawn based on this study show that the dilution temperature influenced the nucleation process and hence its growth. Under the same dilution ratio and residence time, more nucleation mode particles were formed at a temperature of $48^{\circ} \mathrm{C}$ than at $25^{\circ} \mathrm{C}$.

\subsection{Separation of Solid and Volatile Fraction}

PM from diesel engines consists of 3 fractions - solid fraction, soluble organic fraction and a sulfate Fraction. A main challenge for researchers is to be able to come up with a valid sampling methodology to sample the total (solid and volatile) particle number and size 
representative of the atmospheric dilution process. Solid particle size and number measurements can be done to a high degree of accuracy if the sampling system is designed keeping in mind the particle physics and if the volatile fraction can be stripped from the sampling stream prior to measurements. Volatile fraction, by itself is dependent on the factors discussed in the previous sections.

Two methods used by consistently researchers to remove the volatile and semi-volatile fraction are thermo denuders and hot air dilution. These methods are used due to the high temperatures involved which keep the saturation ratios sufficiently low to prevent nucleation.

In a thermo denuder or thermodesorber, the diluted engine exhaust is heated to a temperature $\left(\sim 200{ }^{\circ} \mathrm{C}-300{ }^{\circ} \mathrm{C}\right)$ and then passed to a cooled section which contains an adsorbing agent (usually activated charcoal). The volatile material in the gas phase is adsorbed in this stage and measurements made reflect only the solid fraction of PM. A variety of thermodesorbers are commercially available, For example, TSI Inc. and Dekati Ltd. Research studies conducted with a thermodesorber, by Burscher et al., Kittelson et al., Coutant et al., Fierz et al. [15, 16, 17, 18] among other researchers report efficient removal of the volatile fraction after the diluted exhaust is passed through the thermodesorber.

Terunao Kao et al. [19] conducted experiments on an 8 liter direct injection diesel engine to the influence of cooling and dilution process of nano-particles. Particle number and size distribution were measured using a SMPS in conjunction with a rotary disk type diluter and a full dilution tunnel. Based on the experimental results, it was concluded that hot dilution is preferable compared to cold dilution since the possibility of production of nano-particles with the latter method is highly likely. 


\subsection{Oxidation Catalysts}

Stringent regulations in diesel exhaust emissions have prompted engine manufacturers to modify/change existing engine technology or retrofit engines with aftertreatment devices like oxidation catalysts and diesel particulate filters.

While non-oxidized diesel PM filters primarily keep the PM mass emissions within limitations, oxidation catalysts and catalyzed PM filters have the capability to alter the physical, chemical and biological characteristics of diesel particulate emissions $[1,20]$. The prime purpose of using an oxidation catalyst is to reduce the gaseous and heavy hydrocarbons in the raw exhaust which would in turn reduce the soluble organic fraction (responsible for nuclei mode particles) in the diluted exhaust.

Warner et al. [21] conducted experiments on a Cummins 1988 L10-300 heavy-duty diesel engine retro-fitted with a flow through metallic substrate that used a platinum catalyst of $10 \mathrm{grams} / \mathrm{ft}^{3}$. Engine set points were based on the EPA 13 mode cycle and SMPS measurements made before and after the oxidation catalytic converter, showed that the nuclei mode particle number and volume concentration decreased at idle and Mode 11, and increased at Mode 9. The accumulation mode particle number and volume was found to decrease at idle but increase at Mode 11 and Mode 9.

Baumgard et al. [22] used an oxidation catalytic converter fitted to a 1991 Cummins 10 liter diesel engine and collected data before and after the catalyst to study its effect on diesel emissions. It is concluded in their report that the oxidation catalyst had no effect on the number concentrations and nuclei mode was unaffected since the $\mathrm{H}_{2} \mathrm{SO}_{4}$ vapor pressure was below the threshold for $\mathrm{H}_{2} \mathrm{SO}_{4}-\mathrm{H}_{2} \mathrm{O}$ particle formation. 


\section{EXPERIMENTAL SETUP AND TESTING PROCEDURE}

\subsection{Introduction}

The purpose of this study/thesis was to compare the effects of two different dilution methods, high dilution ratios and an aftertreatment device - oxidation catalyst. The entire testing procedure was carried out at West Virginia University's Engine and Emissions Research Laboratory (EERL). The following chapters gives an overview on the engine specifications, dilution methods used, testing procedure, and instruments used to measure particle size distributions and concentrations.

\subsection{Engine Specifications}

The engine used for this study was a 2005 model Daihatsu diesel engine. It was a 0.953 liter, 3 cylinder (inline) engine with a rated power of $27 \mathrm{hp}$ at $3500 \mathrm{rpm}$. Federal \# 2 diesel was used as fuel for this study and the engine was fitted with a wire mesh oxidation catalyst to study its influence on particle size distributions and concentrations.

\subsection{Dilution System}

The dilution tunnel used for this study was a two-stage mini dilution tunnel setup. The setup consisted of two ejector diluters, one used at each stage with a critical orifice at its inlet (vacuum side). The intention to use a two stage dilution was to achieve high dilution ratios of the order of 500-600.

The ejector diluter used in this study is Model TD-110H vacuum pump, manufactured by Air-Vac Engineering, USA, and commercially sold as a vacuum pump. Figure 3-1 below explains the working principle of an ejector diluter. 


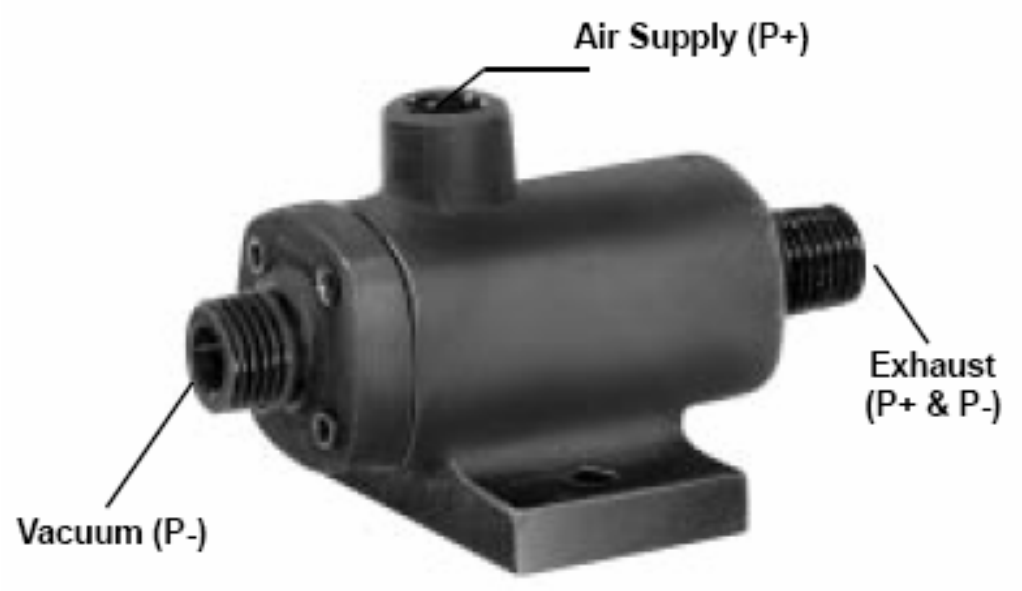

Figure 3-1. Working principle of an Ejector Diluter [23]

Compressed air (dilution air) was passed through the air supply passage $(\mathrm{P}+)$ resulting in a vacuum created at Vacuum (P-) due to rapid expansion. This pressure drop was used to draw the raw exhaust from the engine exhaust stack and dilute it as required. Specifications for the vacuum pump show that vacuum levels up to 25.4 'Hg and vacuum flow rates up to $128 \mathrm{scfm}$ are possible [23].

A range of dilution ratios was achieved by using a combination of critical orifices (2$24 \mathrm{lpm}$ ) and a combination of air pressure (30-80 psi). An orifice was used at the inlet to maintain a constant raw exhaust flow rate which would result in a constant dilution ratio throughout the sampling period. Compressed air was processed through a High Efficiency Particulate Air (HEPA) filter prior to the ejector. A check with the SMPS on HEPA filtered air confirmed that no particles were entrained in the dilution air.

The dilution ratio was calculated based on raw and diluted $\mathrm{CO}_{2}$ measurements which were made before and after dilution of raw exhaust. A California Analytical Model $300 \mathrm{CO}_{2}$ analyzer was used for this purpose. Measurements with the analyzer were possible only for 
lower dilution ratios since higher dilution ratios resulted in a very low concentration of $\mathrm{CO}_{2}$ in the diluted exhaust which was very close to the lower range of the analyzer. Dilution ratios based on $\mathrm{CO}_{2}$ concentrations were complimented well by calculations based on flow rates. Dilution ratio calculations were calculated as follows:

Dilution Ratio $(\mathrm{DR})=$ Raw $\mathrm{CO}_{2}$ Concentration / Dilute $\mathrm{CO}_{2}$ Concentration

Dilution Ratio $(\mathrm{DR})=$ Total Exhaust Flow Rate / Raw Exhaust Flow Rate

Calculations of dilution ratio based on flow rates were made using the manufacturer specifications provided for the TD $110 \mathrm{H}$ ejector diluter [23]. The pressure of compressed air corresponded to a flow rate through the ejector diluter, and raw exhaust flow rate was simply the flow rating of the orifice being used. Due to the observed agreement between the dilution ratios which were determined by the two different methods mentioned above, the flow based method was used throughout the study. Table 3-1 gives the dilution ratios for each stage, and the corresponding orifice flow rate and air pressure used to achieve the dilution ratios.

Table 3-1. Dilution Ratios for Two Stage Mini-Dilution Tunnel

\begin{tabular}{|c|c|c|c|c|c|c|}
\hline \multicolumn{3}{|c|}{ Stage 1 } & \multicolumn{3}{c|}{ Stage 2 } & \\
\hline $\begin{array}{c}\text { Orifice } \\
(\mathbf{I p m})\end{array}$ & $\begin{array}{c}\text { Air pressure } \\
(\mathbf{p s i})\end{array}$ & $\begin{array}{c}\text { Dilution } \\
\text { Ratio }\end{array}$ & $\begin{array}{c}\text { Orifice } \\
(\mathbf{I p m})\end{array}$ & $\begin{array}{c}\text { Air pressure } \\
(\mathbf{p s i})\end{array}$ & $\begin{array}{c}\text { Dilution } \\
\text { Ratio }\end{array}$ & $\begin{array}{c}\text { Total } \\
\text { DR }\end{array}$ \\
\hline 11 & 60 & 12 & 5 & 40 & 20 & 240 \\
\hline 11 & 60 & 12 & 2 & 30 & 42 & 504 \\
\hline
\end{tabular}

The raw exhaust was sampled from the engine exhaust stack using a $J$ type probe. The sample was transferred to the mini-dilution system using a heated line which was maintained at $175^{\circ} \mathrm{C}$ to prevent condensation of hydrocarbons and sampling artifacts associated with the transfer line. . The two dilution methods were cold air dilution and hot air dilution. The cold dilution method comprised of diluting the raw exhaust with cold HEPA filtered dry 
compressed air. Hot dilution method involved heating and maintaining the HEPA filtered dry compressed air within a temperature range of $135{ }^{\circ} \mathrm{C}$ and $145{ }^{\circ} \mathrm{C}$ prior to diluting the raw exhaust. Heating of the dilution air was done using a heated line similar to the one used for transfer of the raw exhaust. Particle size and concentration measurements were conducted on the heated air to ensure zero contamination. The latter method was used to prevent condensation and nucleation of the volatile fraction, thereby, allowing measurements of only the solid fraction of PM.

The dilution ratios used in the study were 240 and 504 as indicated in the table above. The decision to select these dilution ratios was based on extensive preliminary testing performed for a range of dilution ratios from 96-840. SMPS measurements were taken over a range of dilution ratios with the engine operating at intermediate speed and $50 \%$ load (2377 rpm and $24.2 \mathrm{ft}-\mathrm{lb}$ ). The engine exhaust was diluted using the cold dilution method and passed through a thermodesorber, and then sampled with an SMPS. SMPS measurements for the same range of dilution ratios with the engine exhaust diluted using the hot dilution method and comparisons were made with measurements after the thermodesorber. The same is shown in the Figure 3-2. Measurements downstream of the thermodesorber for all the dilution ratios, indicated a large concentration of nuclei mode particles, which was unusually high. The possible reason for this was that the adsorbing agent (activated charcoal) was desorbing previously trapped organics into the dilute exhaust stream which were forming nuclei mode particles. The hot dilution method did not show any nuclei mode particles except at dilution ratios of 774 and 840 . This observation was instrumental in the selection of dilution ratios, 240 and 504, for tests conducted in this study, beyond which dilution ratio had no effect on PM size distributions or concentrations. The lower dilution ratio, 240, allowed for a 
comparison of PM size distribution and concentrations against a higher dilution ratio of 504. The first stage dilution ratio was fixed at 12 since it is in the dilution range of 5:1 to 50:1 which is most favorable to produce nuclei mode particles [10].

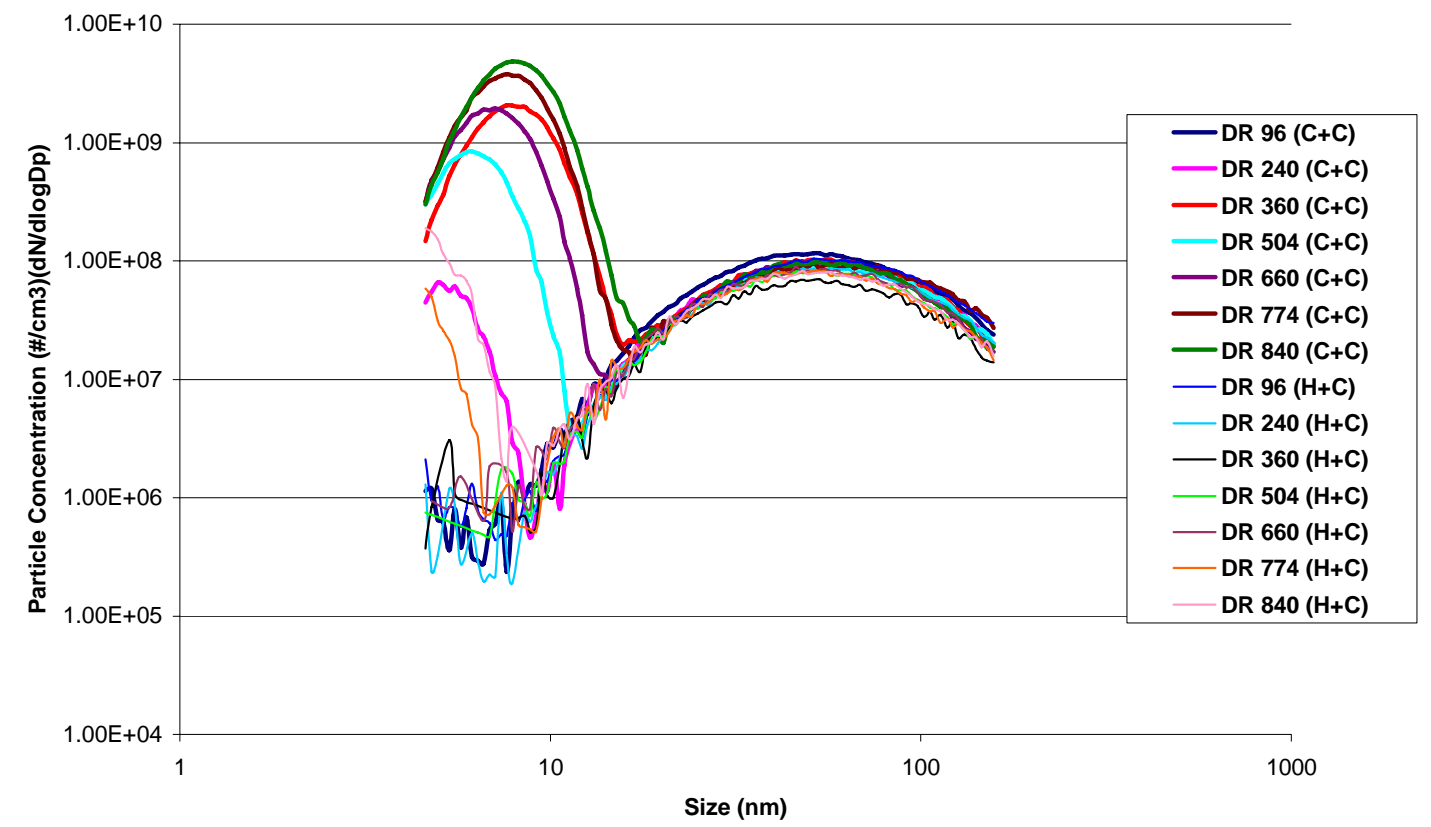

Figure 3-2. DR comparison cold dilution method after thermodesorber at $300{ }^{\circ} \mathrm{C}$ and hot dilution method with engine operating at $2377 \mathrm{rpm}$ and $24.2 \mathrm{ft}-\mathrm{lb}$.

\subsection{PM Sampling Instruments}

The Scanning Mobility Particle Sizer (SMPS) 3936 by TSI Inc. was used to measure the particle size distribution and concentration. The SMPS 3936 is a combination of Electrostatic Classifier 3080 and CPC 3025 A Condensation Particle Counter (CPC) manufactured by TSI Inc. The SMPS was calibrated using a Model 3480 Aerosol Generator by TSI Inc. 


\subsubsection{Scanning Mobility Particle Sizer (SMPS)}

The SMPS 3936 includes an electrostatic classifier used in conjunction with a condensation particle counter. The electrostatic classifier is used to impart a positive charge to the particles and then the $\mathrm{CPC}$ is used to count the concentration of the particles exiting the classifier. The operating specifications of the SMPS 3936 are given in Appendix A of this report.

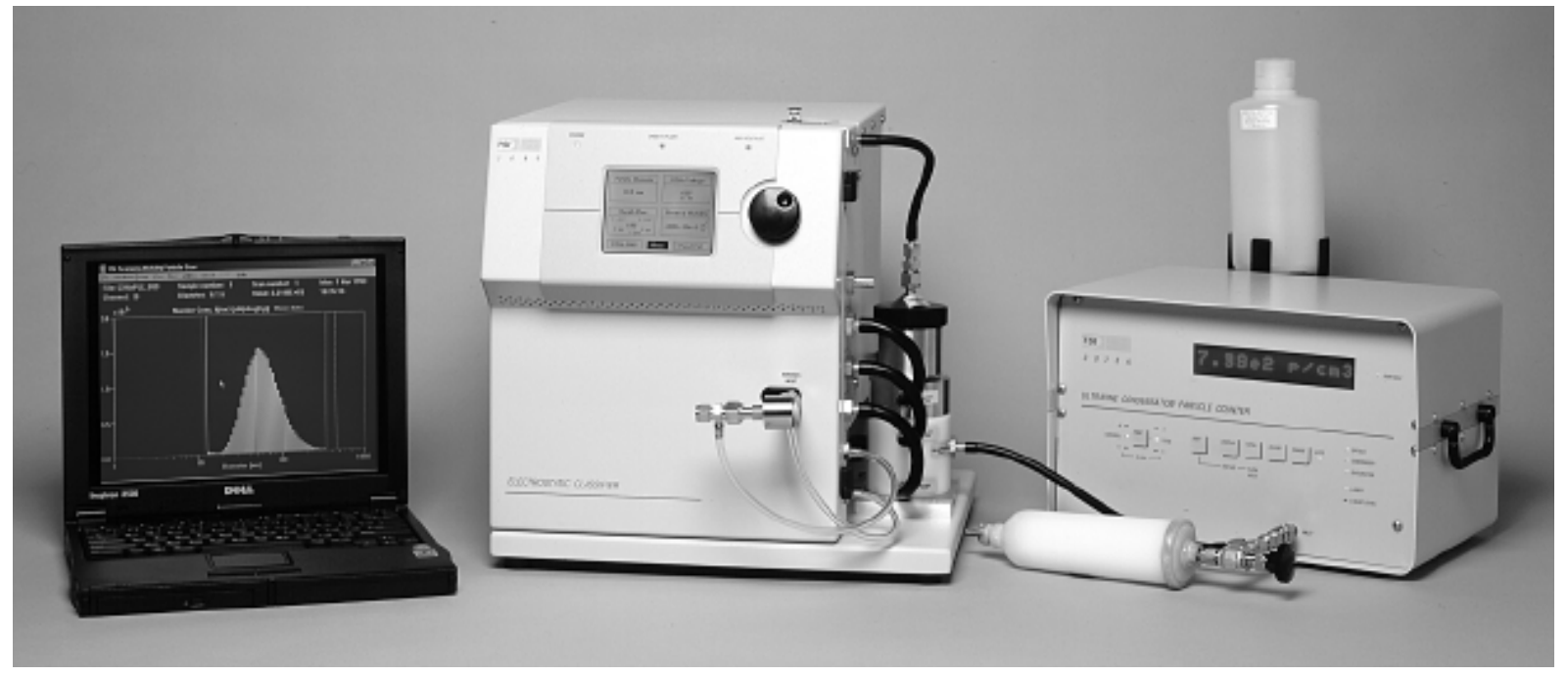

Figure 3-3. SMPS 3936 (Model 3080 Classifier and Model 3025 A CPC) by TSI Inc [24]

The SMPS has been designed for use in basic aerosol research, nanoparticles research, and atmospheric aerosol studies.

The exhaust to be sampled enters the impactor fitted to the inlet of the classifier. The function of an impactor is to remove particles above and below a known particle size by inertial impaction. The sample aerosol is accelerated through a nozzle in the impactor and directed at a flat plate which directs the sample flow to form a $90^{\circ}$ bend in the stream lines. Particles with sufficient inertia are unable to make the $90^{\circ}$ bend and impact on the plate. These particles have sizes above the higher cut point of the impactor. Smaller particles avoid 
impaction and follow the streamlines and the $90^{\circ}$ bend. Figure 3-5 illustrates the inertial impaction theory.

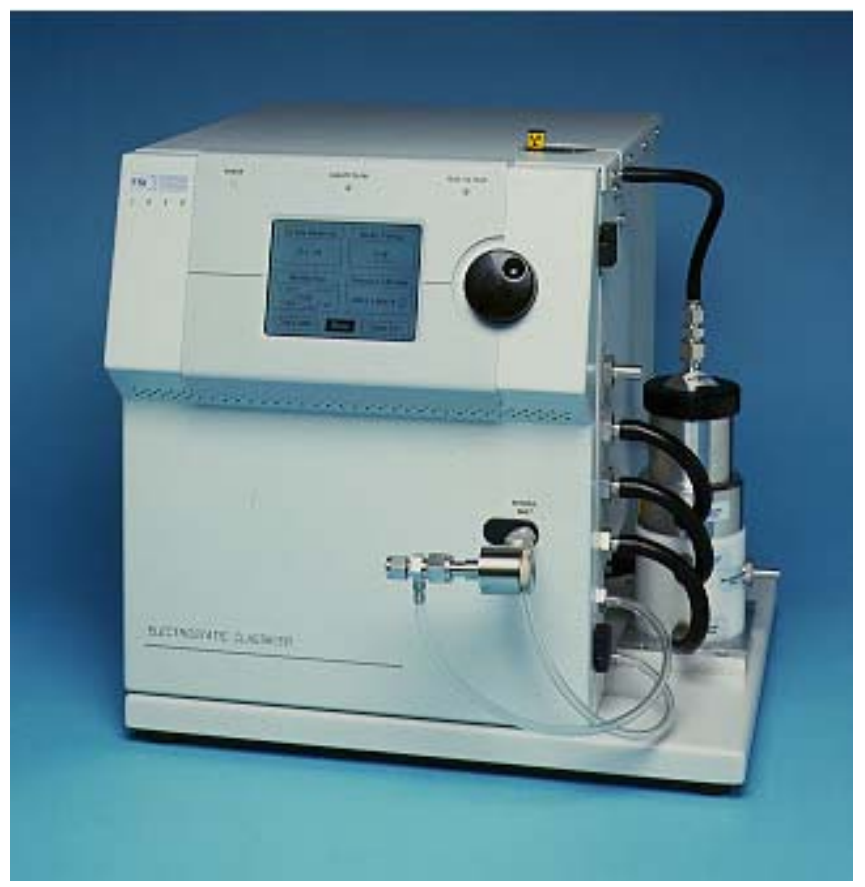

Figure 3-4. Electrostatic Classifier fitted with impactor at inlet [24]

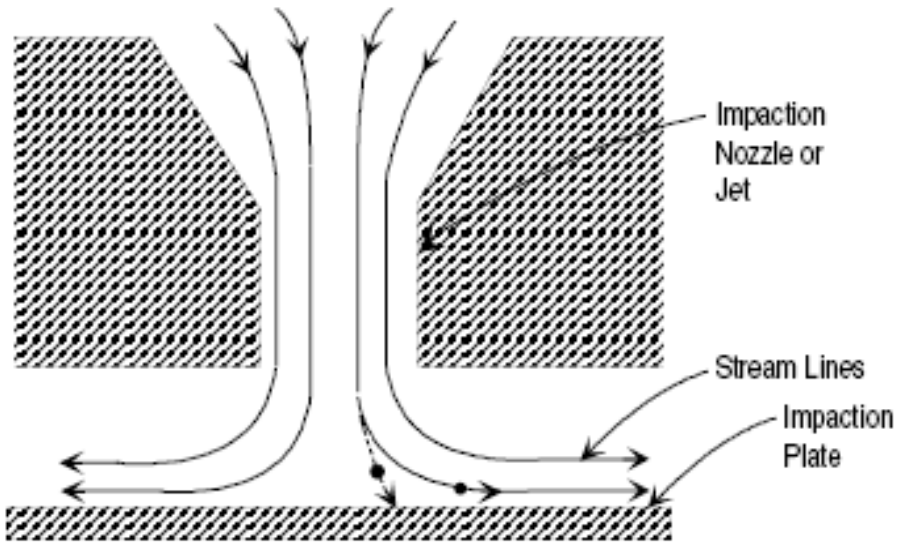

Figure 3-5. Impaction Theory [24]

The purpose of the electrostatic classifier is to extract a known size fraction from the polydisperse sample. After the impactor, the polydisperse aerosol enters a $\mathrm{Kr}-85$ bipolar 
charger or neutralizer which exposes the polydisperse aerosol to high concentrations of bipolar ions. This stage imparts a positive charge to all the particles in the polydisperse aerosol. The basic principle of the electrostatic classifier is that the velocity of a charged particle in an electric field is directly related to the size of the particle. The charged aerosol now enters the Differential Mobility Analyzer (DMA) which consists of two concentric metal cylinders. The inner cylinder is the collector rod which is maintained at a negative potential and the outer cylinder is grounded. This creates an electric field which causes the positively charged particles to be attracted towards the negative potential collector rod. The location of the precipitating particles along the length of the rod depends on the classifier flow rate, particle mobility in an electric field, and classifier geometry. Particles with a higher electric mobility are collected on the upper portion and particles with a lower electric mobility are collected at the lower portion. Particles which have a narrow range of electric mobility exit the DMA as a monodisperse aerosol to the CPC. Figure 3-6 provides a schematic explanation to the working principle of the electrostatic classifier [24]. 


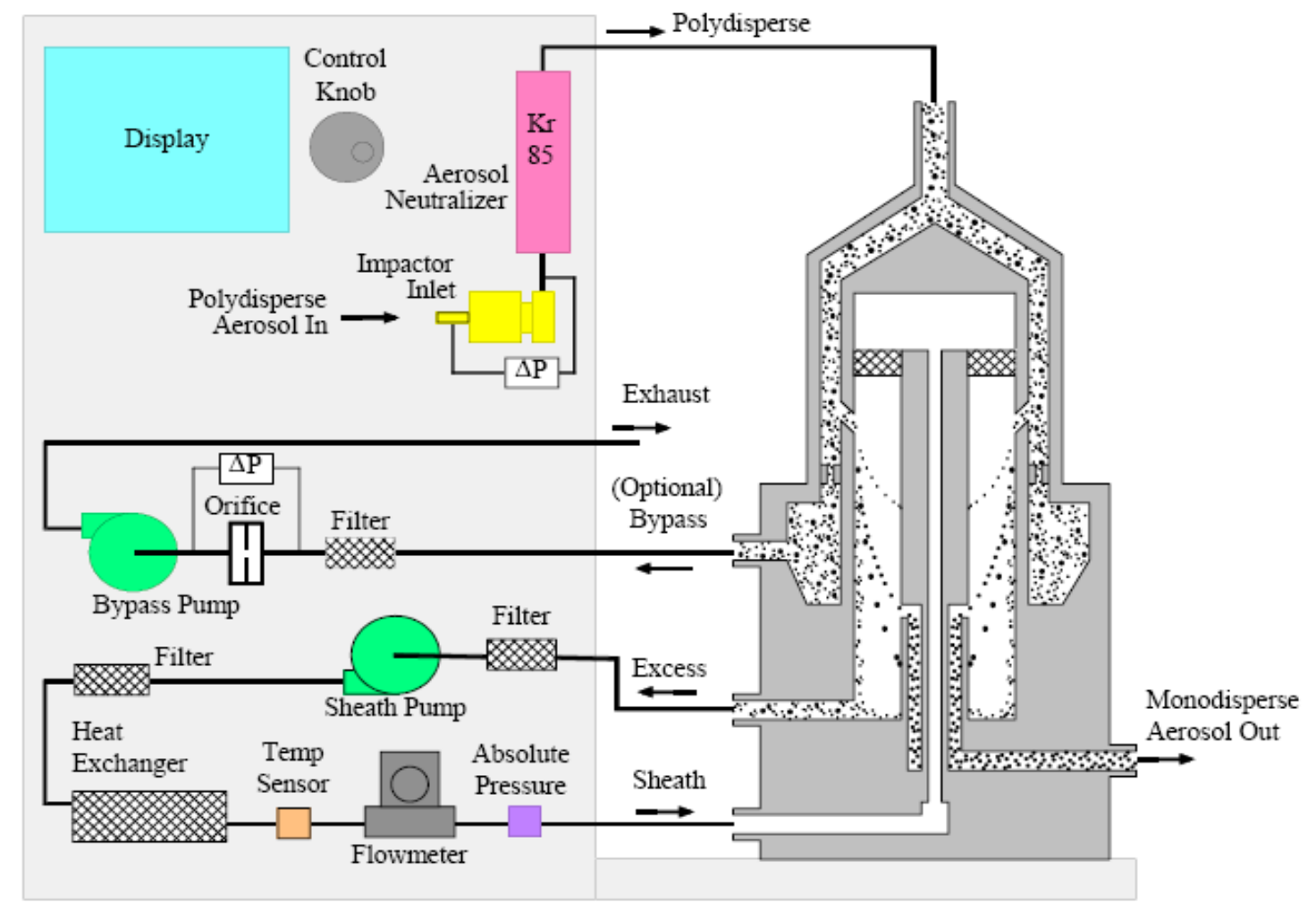

Figure 3-6. Schematic of TSI Inc Model 3480 Electrostatic Classifier with Nano-DMA [24]

The monodisperse aerosol exiting the classifier enters the second unit in the SMPS condensation particle counter. The aerosol is saturated with alcohol vapor as it passes over a heated pool of alcohol (butanol in the case of CPC 3025A). The vapor saturated particles then flow through a condenser where the alcohol condenses onto the particles making them large enough to be optically detectable and counted. The particles now pass through a light beam and scatter light onto a photo-detector which is later translated into a number concentration. Figure 3-7 illustrates the working of a CPC schematically [27]. 


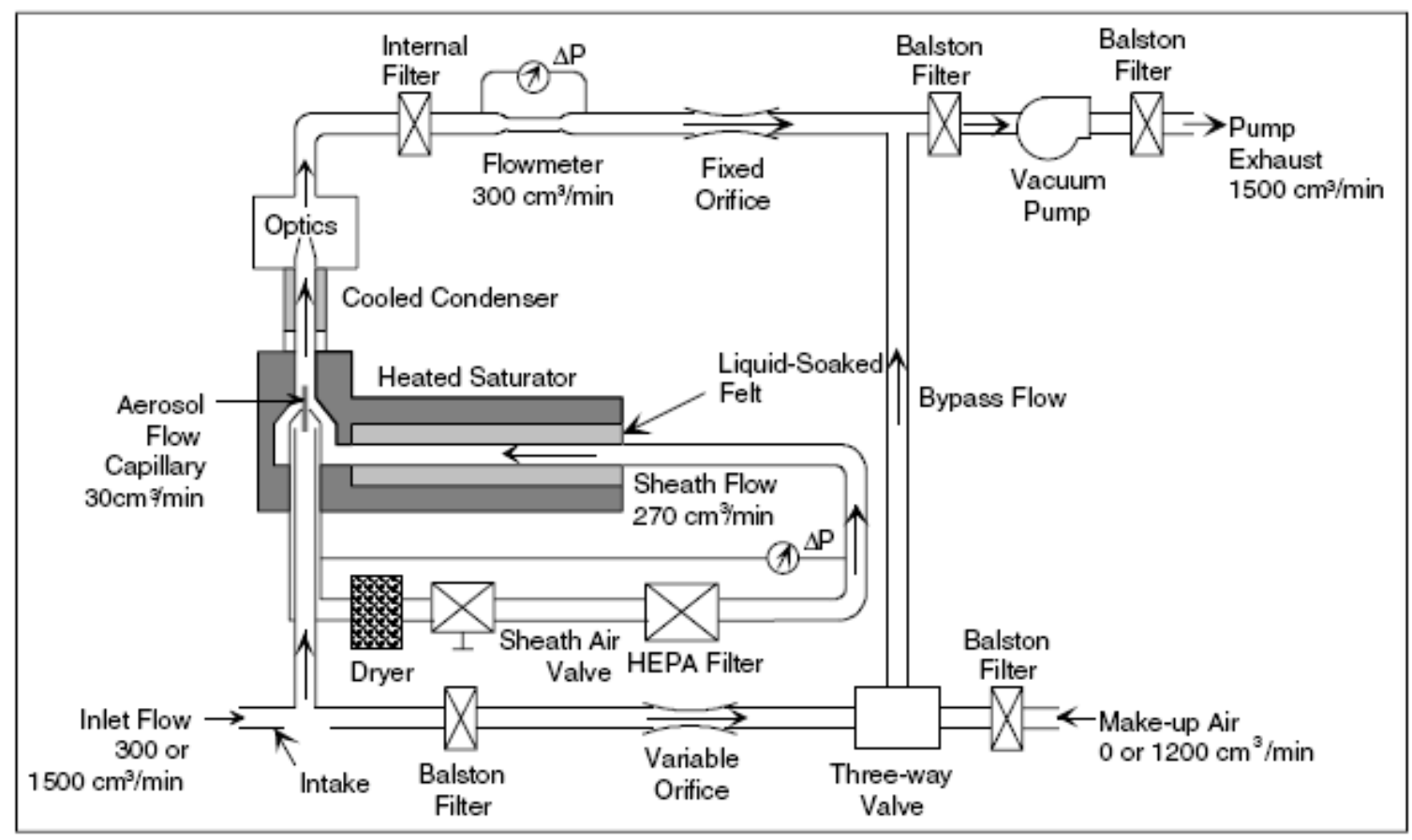

Figure 3-7. Schematic of TSI Inc Model 3025 A Condensation Particle Counter [27]

SMPS 3936 can be used only for steady state operations where the particle concentrations remain constant. Calibration of both the classifier and the $\mathrm{CPC}$ was performed according to the manufacturer specifications. If required, the trouble shooting guides were used to solve any problems interfering with the operation of instrument. The operating specifications of the UCPC 3025 A are given Appendix B of this document [27].

\subsubsection{Model 3480 Electrospray Aerosol Generator}

The TSI Inc. Model 3480 Aerosol Generator was used to calibrate the SMPS 3936. Monodisperse aerosols of three sizes- $15 \mathrm{~nm}, 30 \mathrm{~nm}$, and $70 \mathrm{~nm}$ were produced using sucrose solutions and used for the purpose of calibration. 


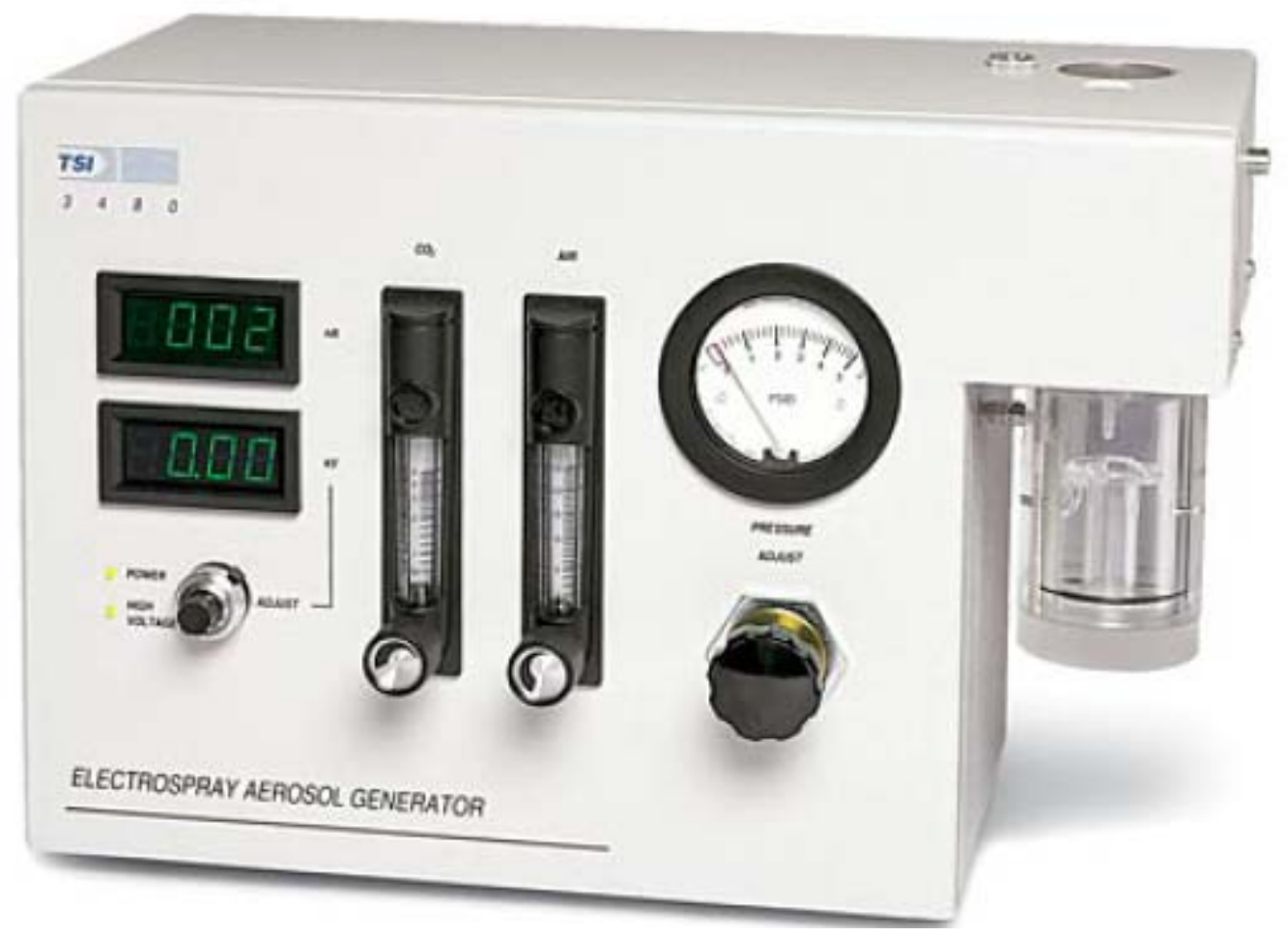

Figure 3-8. TSI Inc. Model 3480 Electrospray Aerosol Generator [25]

The sample sucrose solution is stored in a sample vial (container) and enclosed in a cylindrical pressure chamber. A capillary and high voltage platinum wire is kept immersed in the sample solution. A pressure differential causes the sample solution to flow through the capillary and then the voltage is adjusted until a cone jet is seen in the viewing mode. This is the most ideal formation of aerosol for sampling or for calibration according to the manufacturer specifications. The exiting aerosol droplets are then mixed with HEPA filtered air and $\mathrm{CO}_{2}$ and transported to the electrospray chamber. The charged droplets are now neutralized by a Polonium-210 source and the liquid is evaporated before the aerosol exits the instrument. These single sized charged aerosols can be used for calibrating the SMPS. Figure 3-9 shows a schematic representation of the working of the electrospray aerosol generator [25]. 


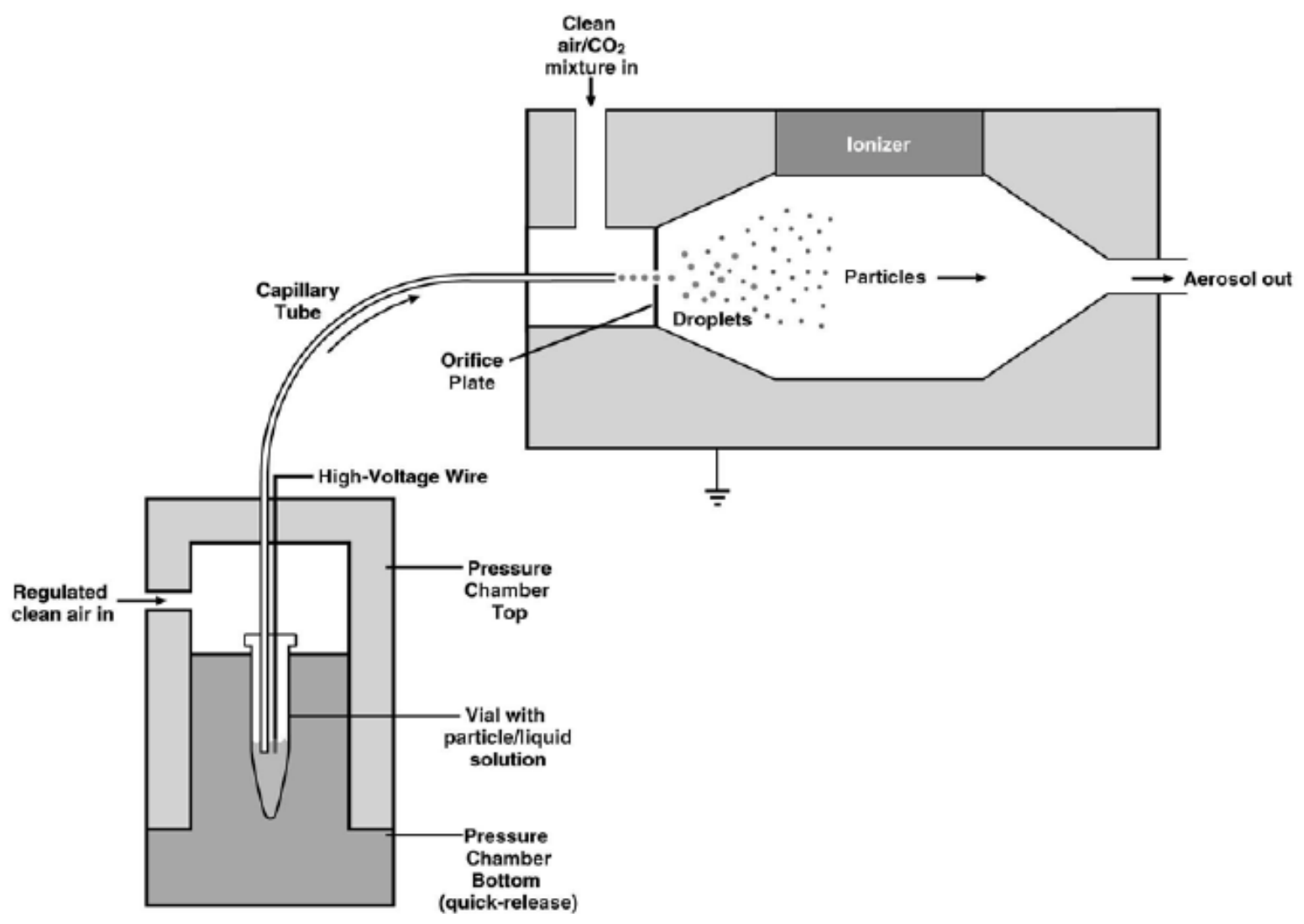

Figure 3-9. Schematic of TSI Inc Model 3480 Electrospray Aerosol Generator [25]

\section{5. $\quad$ Engine Testing and PM Measurement}

A naturally aspirated, mechanically controlled, 3-cylinder inline, 0.953 liter Daihatsu model DM950DTH engine coupled to a eddy current dynamometer was used for testing. Federal diesel \#2 was used for testing and the engine was mapped until 3 repeatable maps were available. The map was used to select a range of engine steady state point which would provide exhaust with different proportions/mixtures of solid and volatile fractions. While choosing the steady state set points the windage losses due to the dynamometer have been accounted for. The engine intake temperature and humidity were kept within a range of 75-80 ${ }^{\circ} \mathrm{F}$ and $48-54 \%$, respectively. The engine was allowed to stabilize for a minimum of 15 
minutes at each set point so as to achieve the optimum raw exhaust and engine oil temperature before sampling.

Raw exhaust sampling was sampled from the transfer tube and transferred to the mini dilution system using a heated line, as described in previous sections. The exhaust was diluted in two stages, with the primary dilution ratio kept constant at 12 and the secondary dilution ratio varied to achieve a combination of total dilution ratios. The difference in the two dilution methods lay in the temperature of air in the primary dilution stage. In the cold dilution method both the stages were involved dilution with cold air, while in the hot dilution method the primary stage dilution was achieved with hot air, and secondary stage dilution was achieved with cold air. At each engine steady state condition, measurements were made for two dilution ratios - 240 and 504, two dilution methods - cold dilution and hot dilution, and before and after the oxidation catalyst. The sample to the SMPS was transferred using tygon tubing in order to eliminate particle losses to the tube wall. A 150 second scan time was selected to measure the entire distribution and this included a 120 second up scan and 30 second down scan. Three repeat scans were conducted for each condition with a gap of 30 seconds between scans. This ensured that the DMA voltage dropped to the minimum, and the instrument was ready to sample.

The particle size distribution given by the TSI Inc. Aerosol Instrument Manager (AIM) software corrects the SMPS raw count data for multiple charges on the particles [26]. The AIM data were corrected for the respective dilution ratio using the reduction program written in MathCAD software. All the particle concentrations reported in this thesis are log normal distributions $(\mathrm{dN} / \mathrm{d} \log \mathrm{Dp})$ of the normalized concentrations (particles $\left./ \mathrm{cm}^{3}\right)$. The program used for dilution ratio correction is given in Appendix C. 
Table 3-2 below gives information about the engine operating set points for which PM size distribution measurements were made. A schematic of the experimental setup is shown in Figure 3-10.

Table 3-2. Engine Steady State Set Points

\begin{tabular}{|c|c|c|}
\hline $\begin{array}{c}\text { Engine Set } \\
\text { Point }\end{array}$ & $\begin{array}{c}\text { Torque } \\
\text { (ft-lb) }\end{array}$ & $\begin{array}{c}\text { Speed } \\
\text { (rpm) }\end{array}$ \\
\hline I 50 & 24.20 & 2377 \\
\hline I 100 & 48.41 & 2377 \\
\hline R 50 & 22.00 & 3343 \\
\hline R 100 & 44.00 & 3343 \\
\hline
\end{tabular}

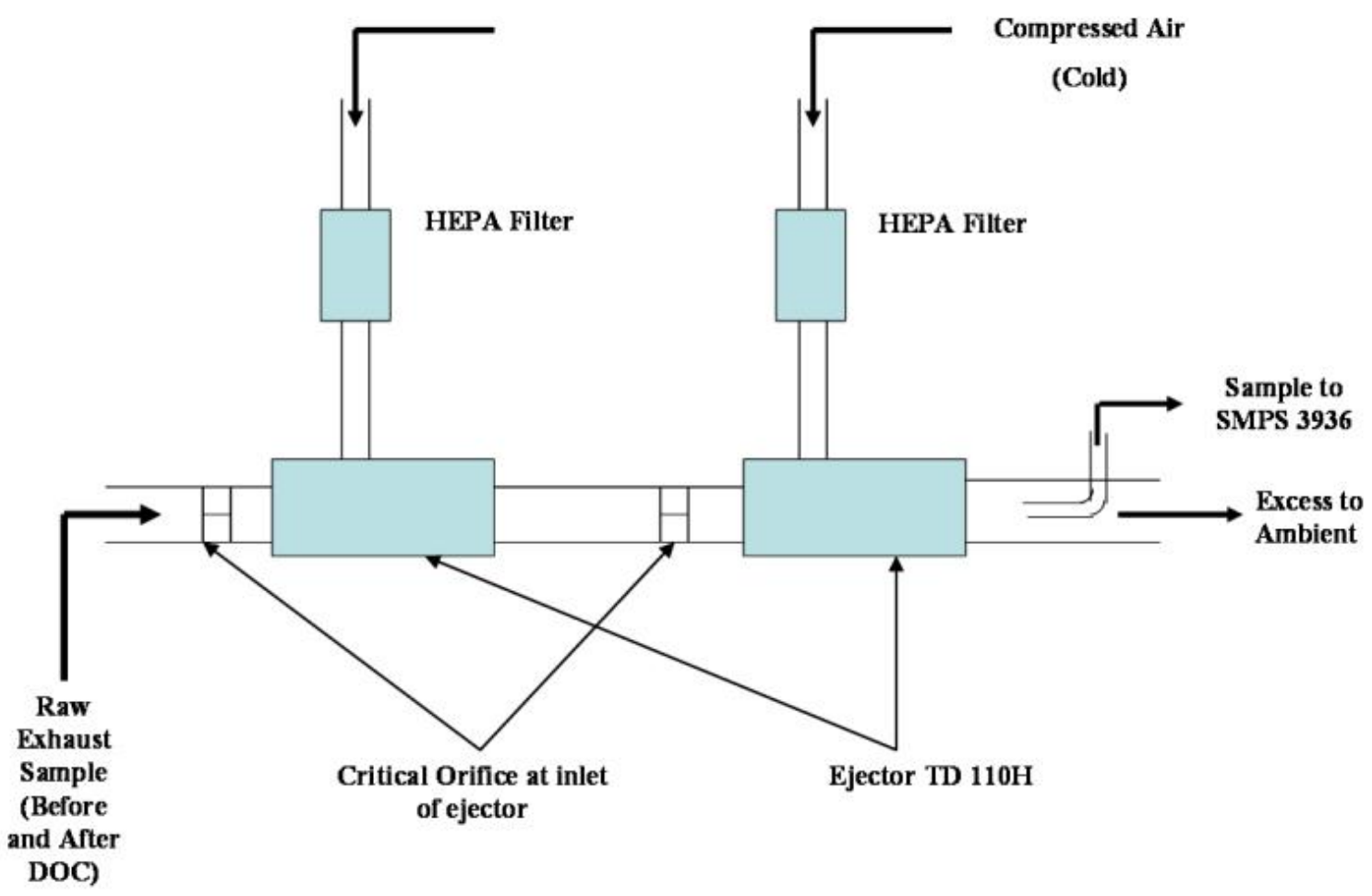

Figure 3-10. Schematic of Experimental Setup. 


\section{RESULTS AND DISCUSSIONS}

\subsection{Introduction}

Particle concentration and size distribution measurements were made at all the set points described in the previous section at two dilution ratios - 240 and 504, with and without an aftertreatment device-oxidation catalyst. This chapter discusses in detail the results obtained and the conclusions drawn from them.

\subsection{Steady State Testing}

The influence of the dilution method, dilution ratio and the oxidation catalyst was studied at all the engine set points chosen for this study. The table below gives the test matrix adopted in this study.

Table 4-1. Steady State Test Matrix

\begin{tabular}{|c|c|c|c|c|c|c|}
\hline \multirow{2}{*}{ Engine Set Pont } & \multicolumn{2}{|c|}{ Dilution Method } & \multicolumn{2}{c|}{ Dilution Ratio } & \multicolumn{2}{c|}{ Oxidation Catalyst } \\
\cline { 2 - 6 } $\begin{array}{c}\text { I } 50 \\
24.20 \mathrm{ft}-\mathrm{Ib}, 2377 \mathrm{rpm}\end{array}$ & Cold & Hot & 240 & 504 & Before & After \\
\hline $\begin{array}{c}\text { I } 100 \\
48.41 \mathrm{ft}-\mathrm{Ib}, 2377 \mathrm{rpm}\end{array}$ & $\times$ & $\times$ & $\times$ & $\times$ & $\times$ & $\times$ \\
\hline $\begin{array}{c}\text { R } 50 \\
22.00 \mathrm{ft}-\mathrm{Ib}, 3343 \mathrm{rpm}\end{array}$ & $\times$ & $\times$ & $\times$ & $\times$ & $\times$ & $\times$ \\
\hline $\begin{array}{c}\text { R } 100 \\
44.00 \mathrm{ft}-\mathrm{Ib}, 3343 \mathrm{rpm}\end{array}$ & $\times$ & $\times$ & $\times$ & $\times$ & $\times$ & $\times$ \\
\hline
\end{tabular}




\subsection{Influence of Dilution Method}

The comparison of the cold dilution and the hot dilution method was studied by taking measurements before the oxidation catalyst (BOC). Set points and dilution ratios chosen are as per Table 4-1. $\mathrm{H}+\mathrm{C}$ indicates the hot dilution method (first stage hot dilution and second stage cold dilution) and $\mathrm{C}+\mathrm{C}$ (cold dilution in both stages) indicates the cold dilution method.

\subsubsection{Dilution Ratio 240}

The primary dilution stage was set at a dilution ratio of 12 , which is in the dilution range most preferable to achieve high saturation ratios and thus nucleation mode particles, and the secondary dilution stage was set at 20 , so as to dilute the exhaust quickly to a high dilution ratio to stop nucleation and slow coagulation, to achieve an overall dilution ratio of 240.

Figure 4-1 shows the results for an engine set point of I 50 (24.2 ft-lb @ 2377 rpm) for both the dilution methods at the same dilution ratio of 240 .

The size distribution for the hot dilution method has a Count Median Diameter (CMD) of $53.3 \mathrm{~nm}$ with a total concentration of $8.24 \times 10^{7} \# / \mathrm{cm}^{3}$ compared to a CMD of $44.5 \mathrm{~nm}$ and total concentration of $8.56 \times 10^{7} \# / \mathrm{cm}^{3}$ for the cold dilution method. The hot dilution method shows a lower concentration of nucleation mode particles than the cold dilution method. Although there is a small shift in the distribution in the accumulation mode, the change in concentrations is not significant. The reduced nucleation mode particles in the hot dilution method are due to the high dilution temperature compared to the cold dilution method. This is due to the fact that the high dilution air temperature prevents the saturation ratio from achieving a maximum and thus preventing nucleation of particles. 


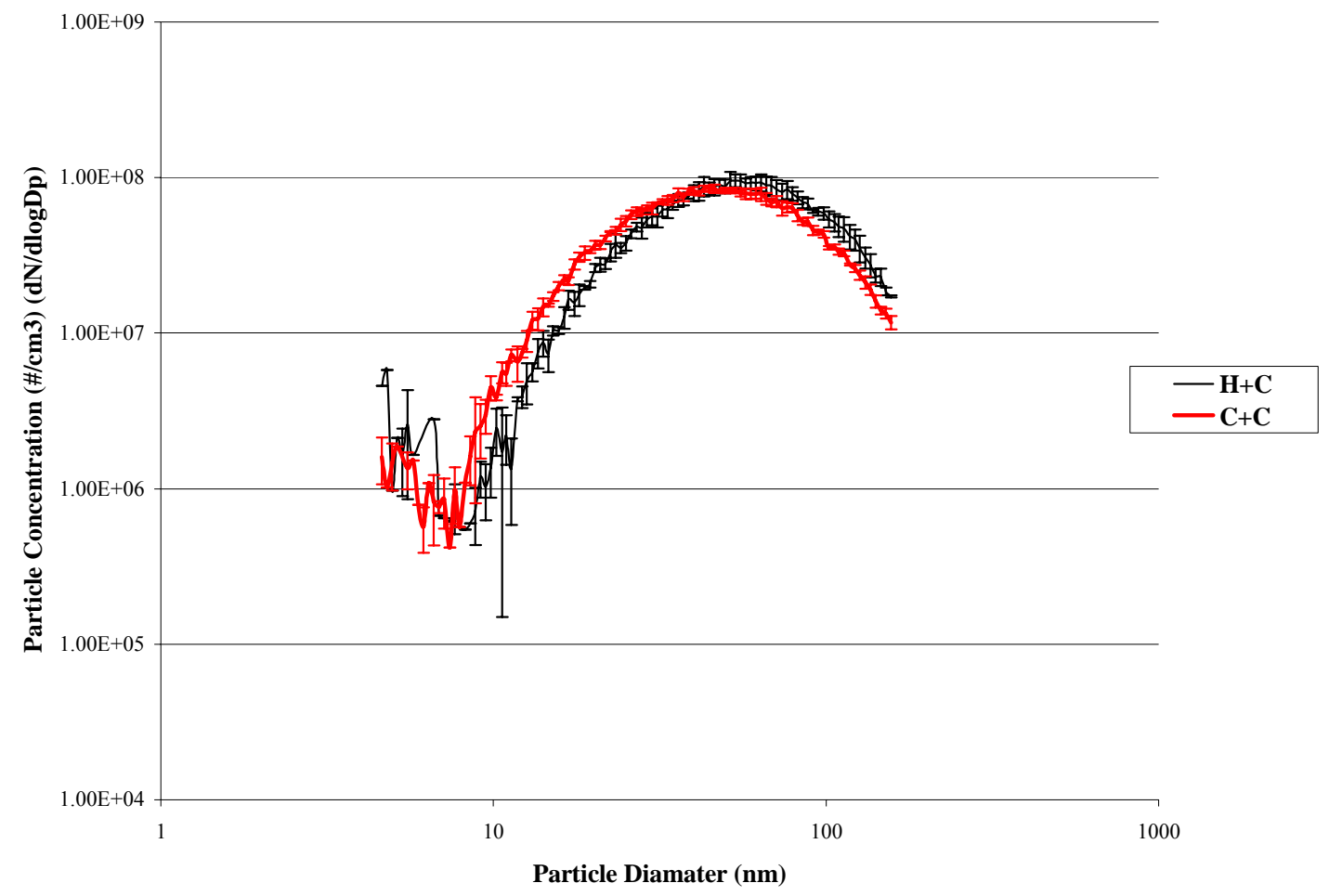

Figure 4-1. Particle Size Distribution at I 50 engine set point, DR 240, Cold Vs Hot Dilution Method

Figure 4-1 also shows the standard deviations $(1 \sigma)$ calculated from the concentrations of 3 SMPS scans. The observed errors are significant in the nucleation mode due to the very high sensitivity of this mode thus hampering repeatable scans. The standard deviation observed for particles in the accumulation mode are within a $1 \%$ error, which is acceptable.

Figure 4-2 shows the results for an engine set point of I 100 (48.41 ft-lb @ 2377 rpm) for both the dilution methods at the same dilution ratio of 240 .

The size distributions for both the cold and hot dilutions are similar with the CMD of $49.6 \mathrm{~nm}$ and the total particle concentration for both the methods almost the same. Compared to the size distribution in Fig 4-1, the possible reason for the similarity in the distributions is due to lesser volatile species at this engine set point. 


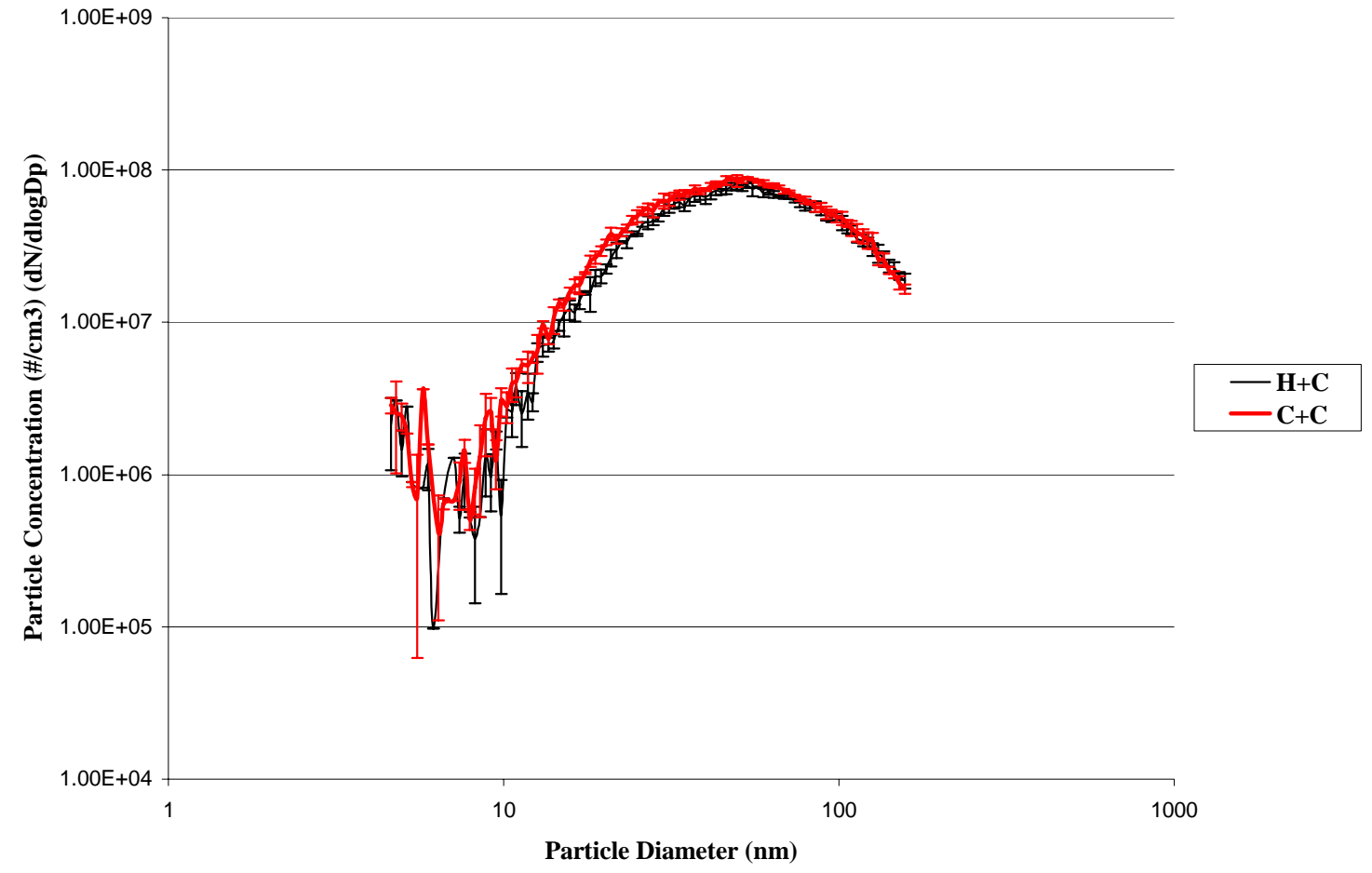

Figure 4-2. Particle Size Distribution at I 100 engine set point, DR 240, Cold Vs Hot Dilution Method

Figure 4-3 shows the particle size distributions with the concentrations for an engine operating point R50 (22 ft-lb @ $3343 \mathrm{rpm}$ ) for both the dilution methods at a dilution ratio of 240. The CMD in the accumulation mode for both the methods are very much similar at 55.2 $\mathrm{nm}$ considering that this engine operating point is known to produce more particles in this mode and less of organics although there is a difference in the total concentration with $1.55 \times 10^{8} \mathrm{\#} / \mathrm{cm}^{3}$ for the cold dilution method and $1.03 \times 10^{8} \mathrm{\#} / \mathrm{cm}^{3}$ for the hot dilution method. The effect of dilution temperature can be seen in this graph where the volatile organics have not been allowed to settle on the existing solid particles and prevention of formation of nucleation mode particles. 


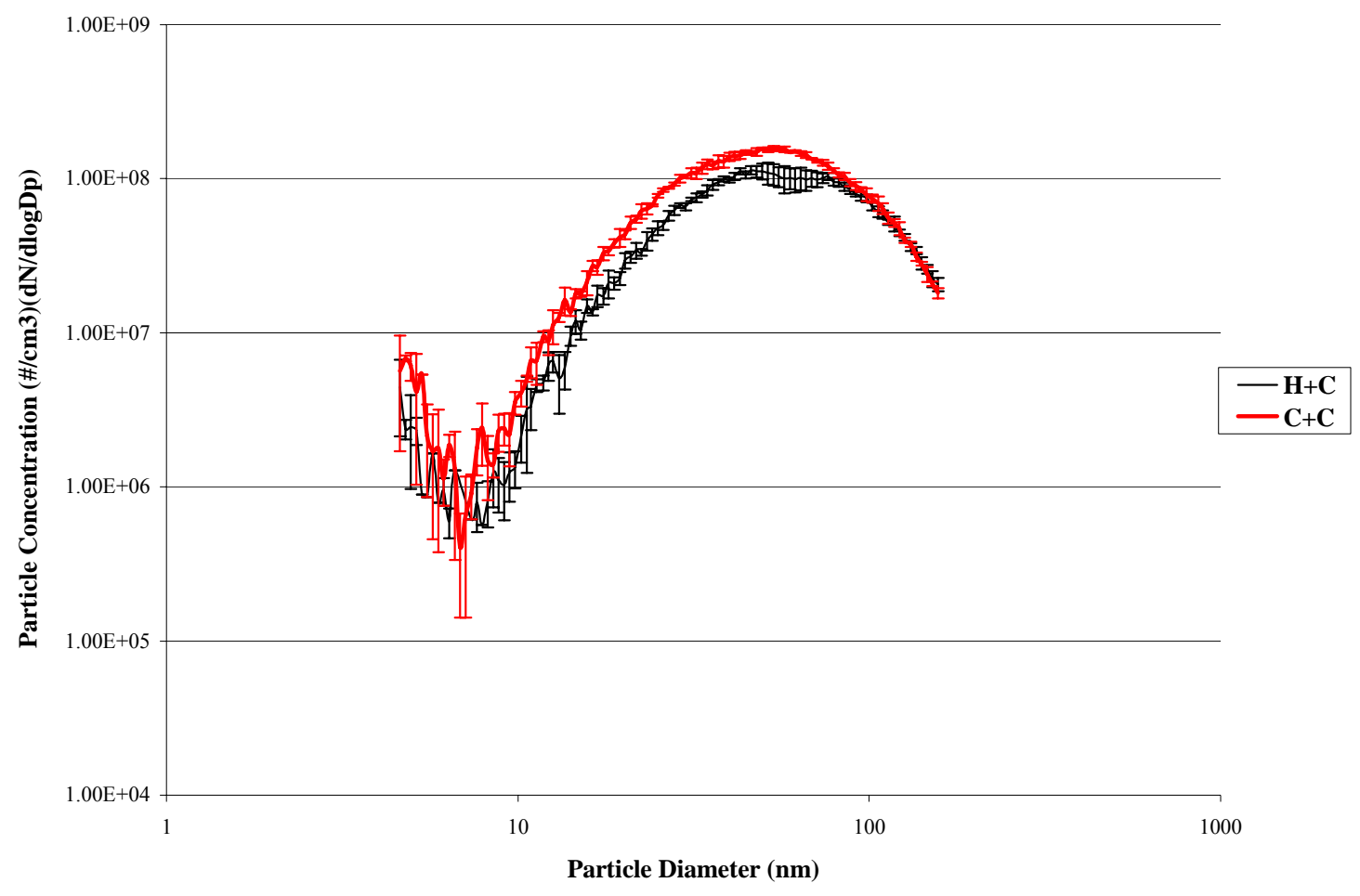

Figure 4-3. Particle Size Distribution at $R 50$ engine set point, DR 240, Cold Vs Hot Dilution Method

Figure 4-4 shows the results for the particle size distributions measured at an engine set point of R100 (44 ft-lb @ $3343 \mathrm{rpm}$ ) for both dilution methods at the same dilution ratio of 240 .

Size distributions show that results are similar to those shown in Fig 4-3 although the total concentrations have been reduced negligibly.

The errors or deviations from the average observed for all the compared data were large in the nucleation mode compared to the accumulation mode where the errors are within acceptable range. 


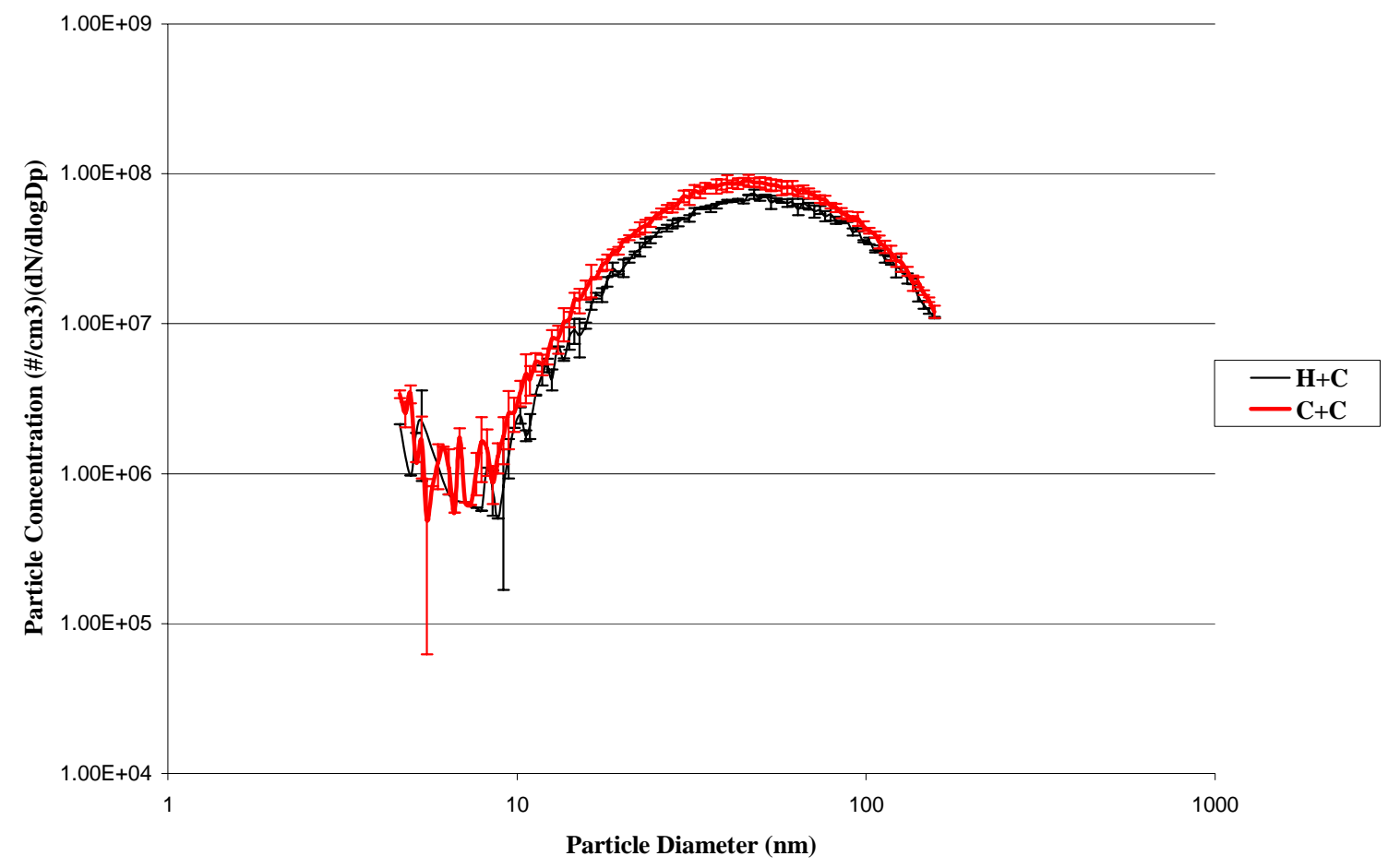

Figure 4-4. Particle Size Distribution at R 100 engine set point, DR 240, Cold Vs Hot Dilution Method

\subsubsection{Dilution Ratio 504}

The primary dilution stage was set at a dilution ratio of 12 and the secondary dilution stage was set at 42 to achieve an overall dilution ratio of 504 .

Fig 4-5 shows the particle size distributions for an engine operating point of I 50 (24.2 ft-lb @ 2377 rpm) for both the dilution methods at a similar dilution ratio of 504.

Results are consistent with what has been discussed in Section 2.5.1 of this thesis where the dilution ratio does not have any pronounced effect on the accumulation mode particles and concentration of nucleation mode particles is less with increasing dilution ratio. The dilution method does not make a difference as can be seen from the graph below. 


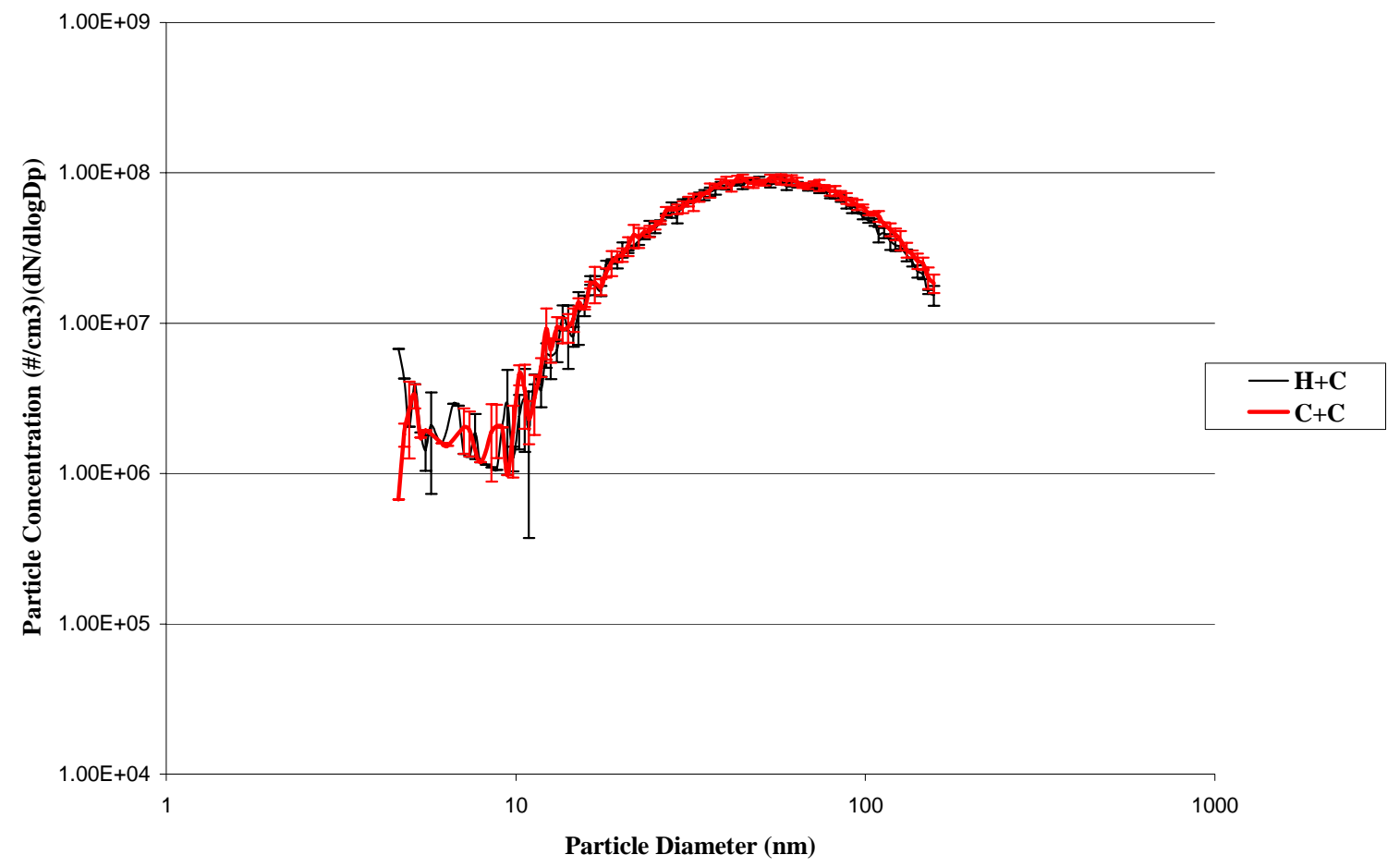

Figure 4-5. Particle Size Distribution at I 50 engine set point, DR 504, Cold Vs Hot Dilution Method

Figure 4-6 shows the particle size distributions for an engine operating set point of I 100 ( 48.41 ft-lb @ 2377 rpm) for both the dilution methods at a dilution ratio of 504.

The influence of the dilution method has no effect in the PM distribution measurement for the same reason cited above for results shown in Figure 4-5. 


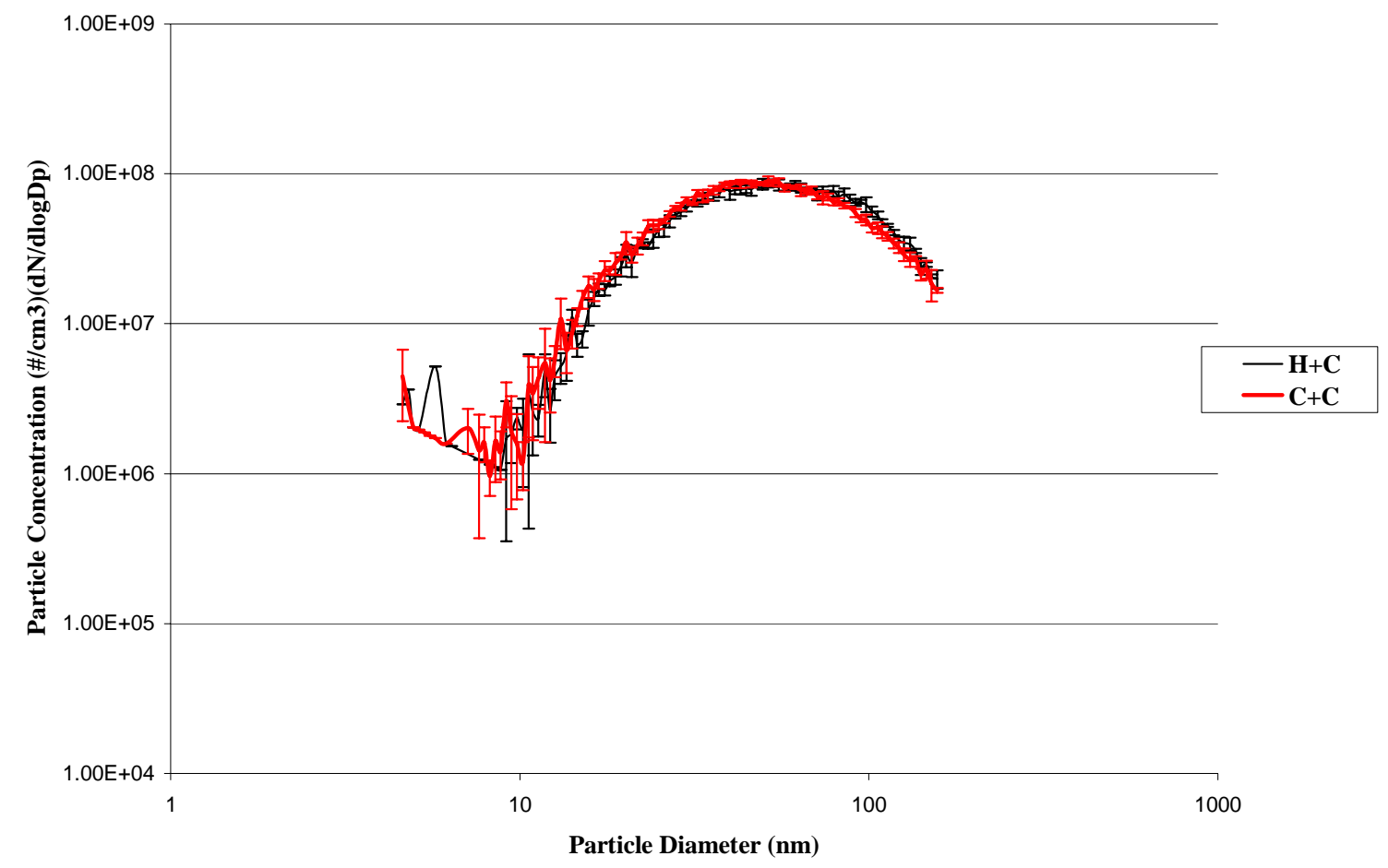

Figure 4-6. Particle Size Distribution at I 100 engine set point, DR 504, Cold Vs Hot Dilution Method

Figure 4-7 shows the measurements taken at an engine operating point of R 50 (22 ftlb@3343 rpm).

Size distributions are similar to what has been obtained in Fig 4-5 for an I 50 mode. The influence of the dilution method on the particle size distribution and concentrations is not pronounced although a very small negligible change in concentration can be noticed.

Figure 4-8 compares the particle size distributions at an engine operating point of R 100 (44.1 ft-lb@3373 rpm). 
Size distribution profiles for both the methods are almost identical, indicating that there was a minimal amount of volatile material in this mode for the dilution method to have an influence.

The errors observed for all the data for a dilution ratio of 504 and all the engine operating points are similar to that observed for a dilution ratio of 240. Errors, as discussed previously, were comparatively large only in the nucleation mode and not in the accumulation mode.

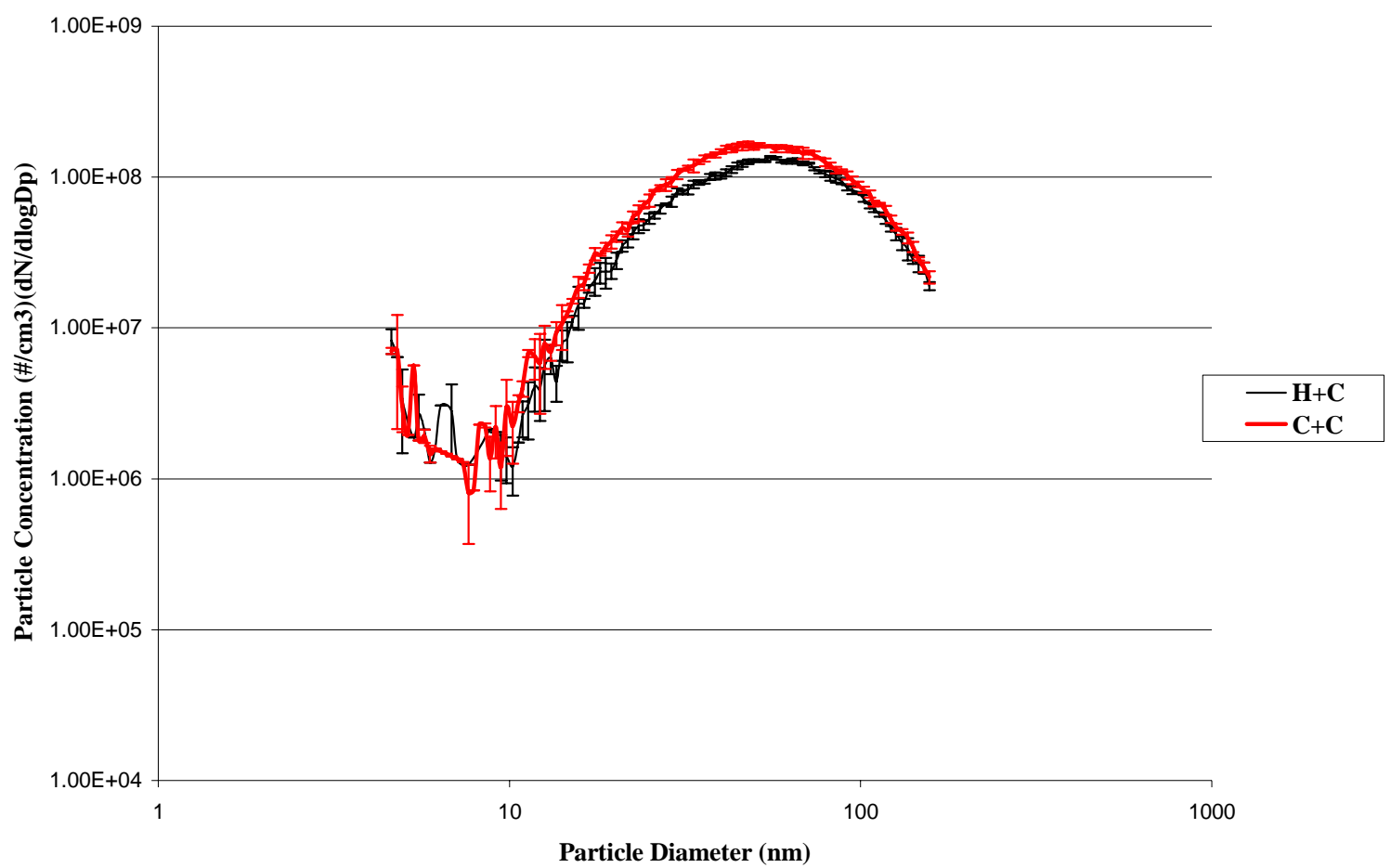

Figure 4-7. Particle Size Distribution at R 50 engine set point, DR 504, Cold Vs Hot Dilution Method 


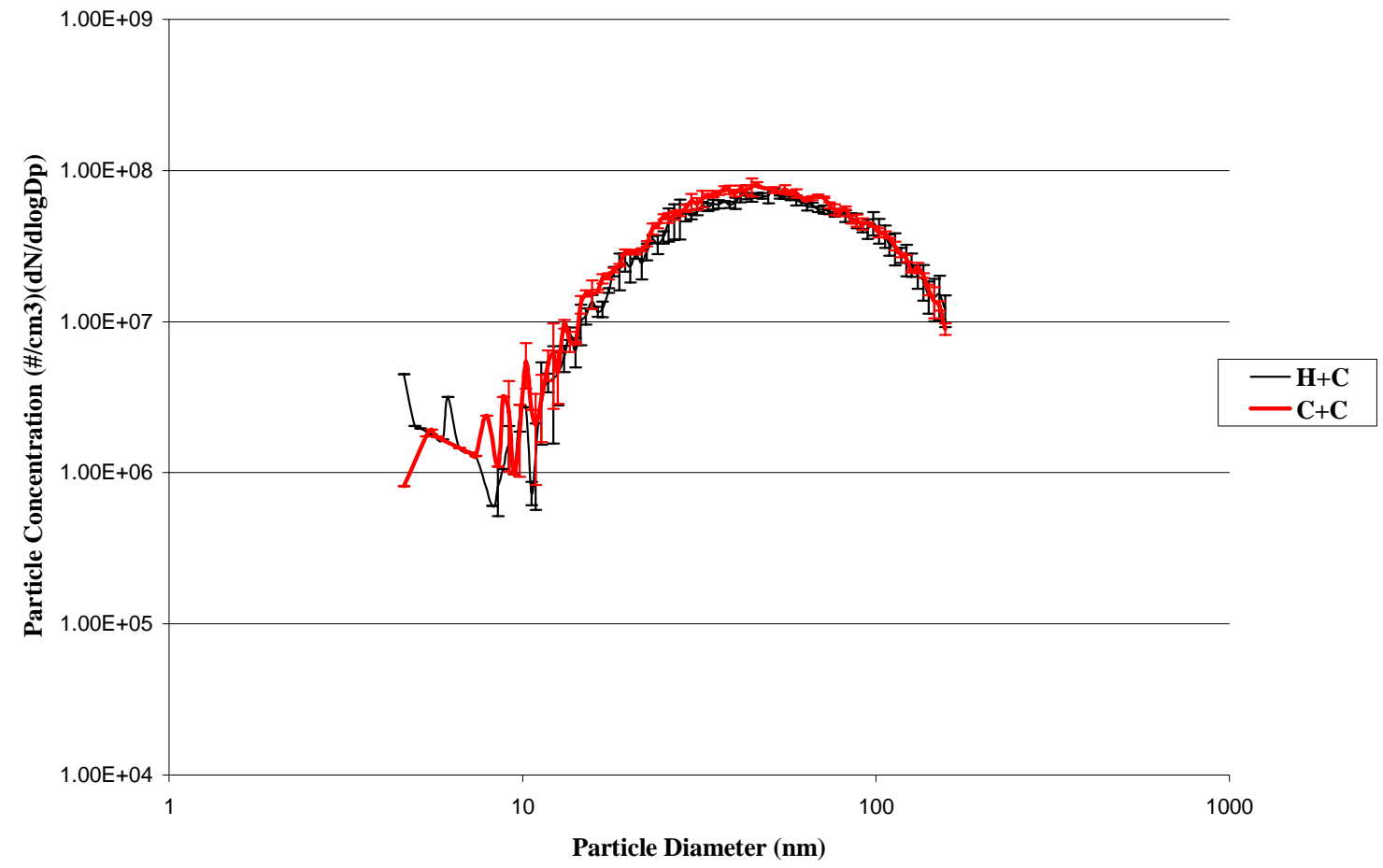

Figure 4-8. Particle Size Distribution at R 100 engine set point, DR 504, Cold Vs Hot Dilution Method

\subsection{Influence of Dilution Ratio}

The influence of dilution ratio on particle size distributions and concentrations was studied. SMPS measurements were made before the oxidation catalyst (BOC) for both the dilution methods, hot and cold, for dilution ratios 240 and 504. The engine set points were chosen as shown in Table 4-1.

\subsubsection{Engine Set Point I 50}

Fig 4-9 shows the particle size distributions for dilution ratios 240 and 504 with the engine operating in I 50 mode ( $24.2 \mathrm{ft}-\mathrm{lb} @ 2377 \mathrm{rpm})$. 


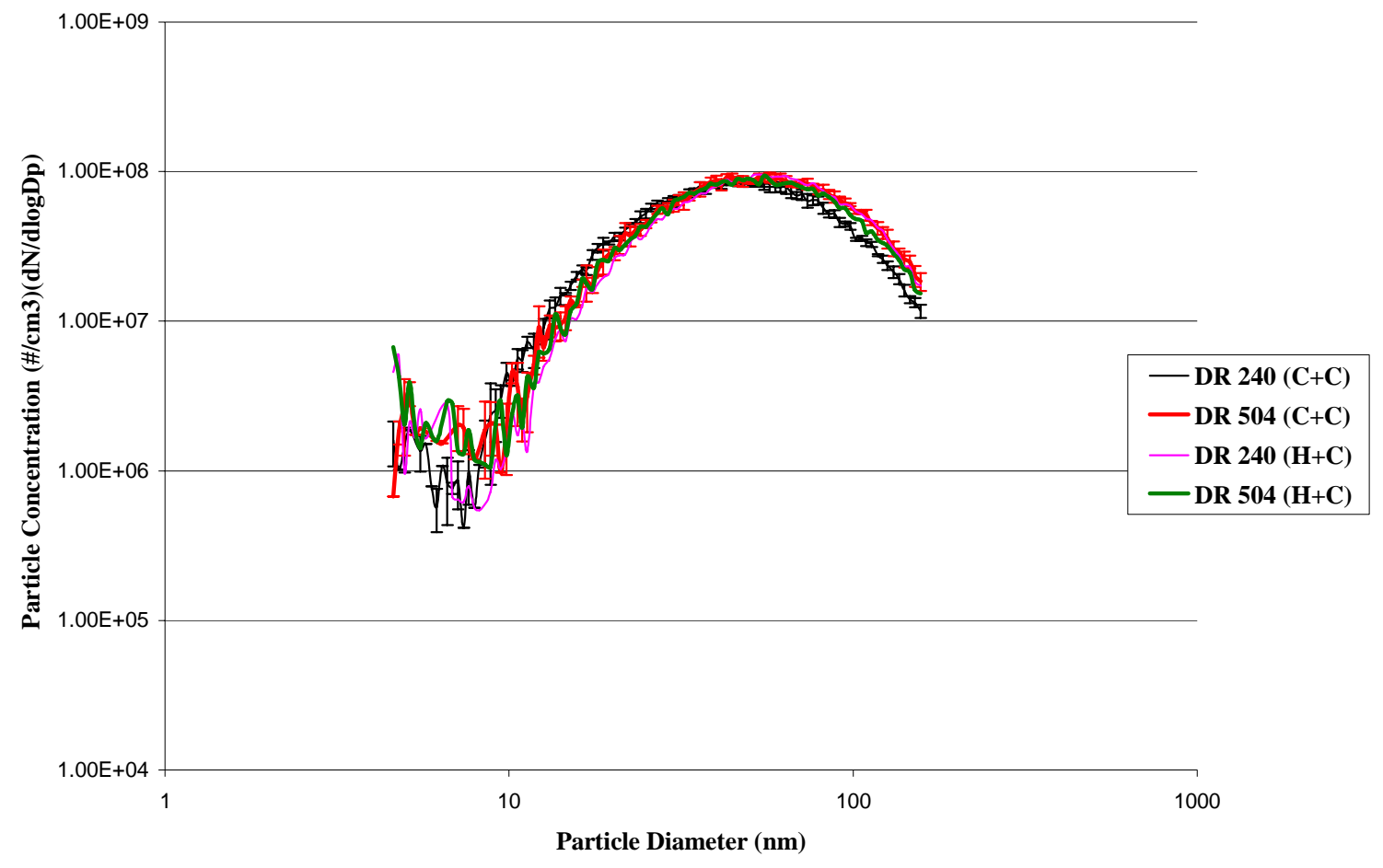

Figure 4-9. Particle Size Distribution at I 50 engine set point, Cold Dilution Method, DR 240 Vs DR 504

Fig 4-9 shows that the influence of dilution ratio on the size distribution or the concentration is minimal. Dilution ratio (high or low), as discussed in previous chapters, does not affect the accumulation mode. However there is an observed shift in the size distribution and change in concentration between the two dilution methods. This has been discussed in the previous section.

\subsubsection{Engine Set Point I 100}

Figure 4-10 shows the particle size distribution comparison for dilution ratios 240 and 504 with the engine operating in I 100 mode (48.41 ft-lb @ 2377 rpm). 


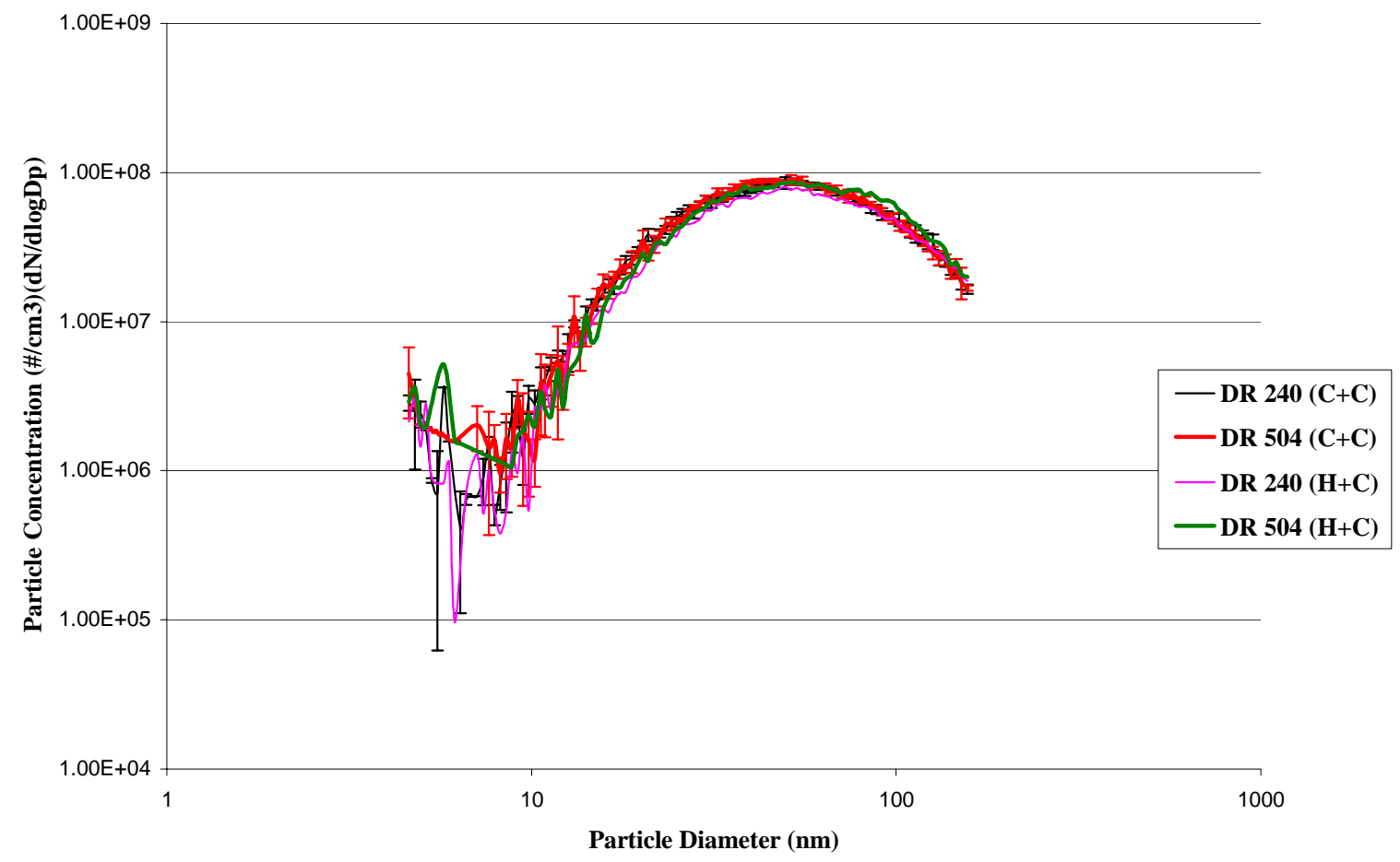

Figure 4-10. Particle Size Distribution at I 100 engine set point, Cold Dilution Method, DR 240 Vs DR 504

The errors have been plotted only for the cold dilution method so as to be able to analyze the graph legibly. Observed errors are large only in the particle diameter range of $4.65 \mathrm{~nm}$ to $20 \mathrm{~nm}$. Dilution ratio based on a particular dilution method has no noticeable effect on the distribution and concentration.

\subsubsection{Engine Set Point R 50}

Figure 4-11 compares particle size distribution and concentrations for the engine operating in the R 50 mode.

A slightly higher concentration is seen in the accumulation mode as expected but there is hardly any noticeable influence of the dilution ratio on the measurements obtained. 


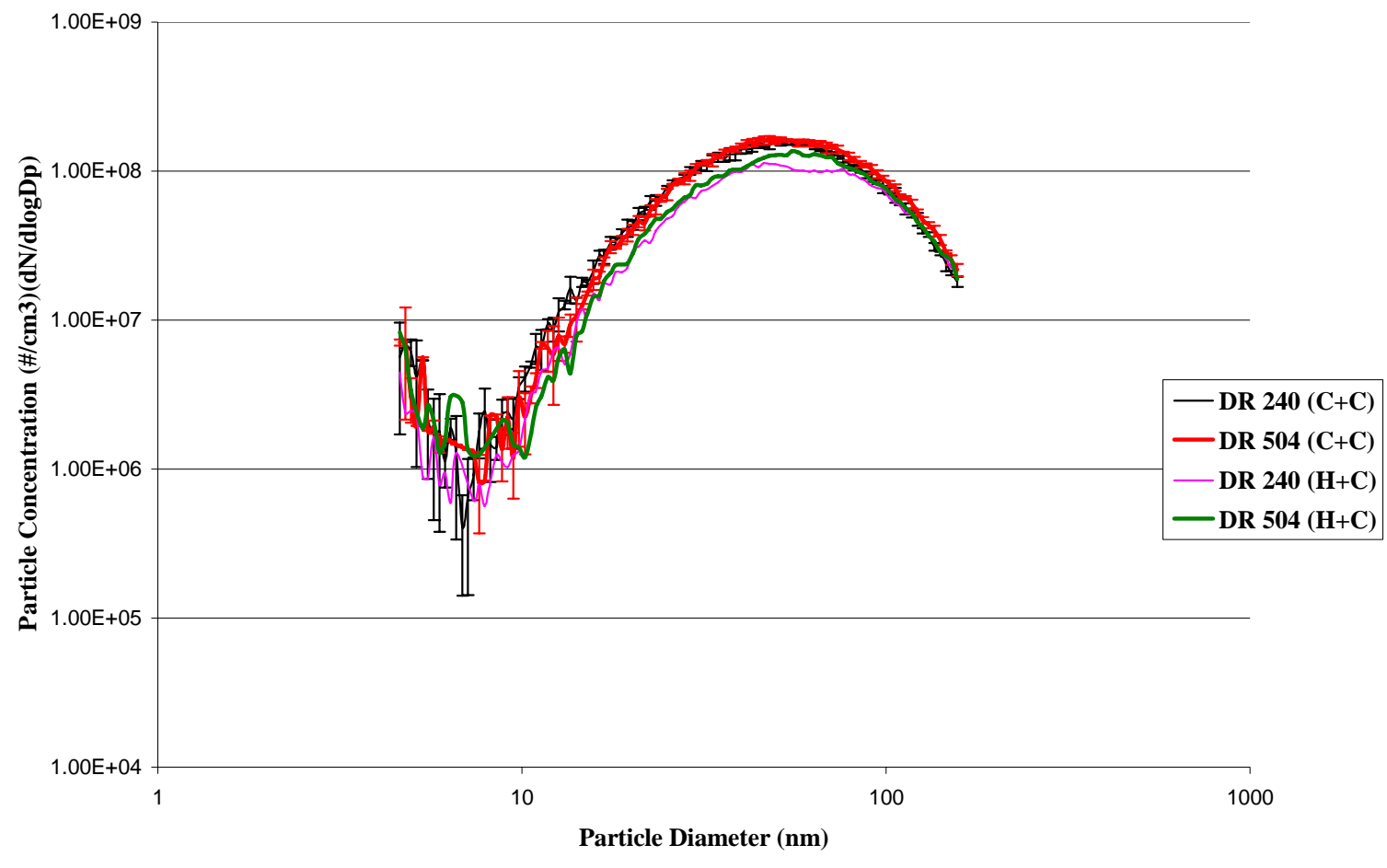

Figure 4-11. Particle Size Distribution at R 50 engine set point, Cold Dilution Method, DR 240 Vs DR 504

\subsubsection{Engine Set Point R 100}

Figure 4-12 compares the particle size distributions and concentrations with the engine operating in the R 100 mode.

The distributions for the two dilution ratios are almost similar to confirm that there is hardly any noticeable influence of high dilution ratios on the measured data. 


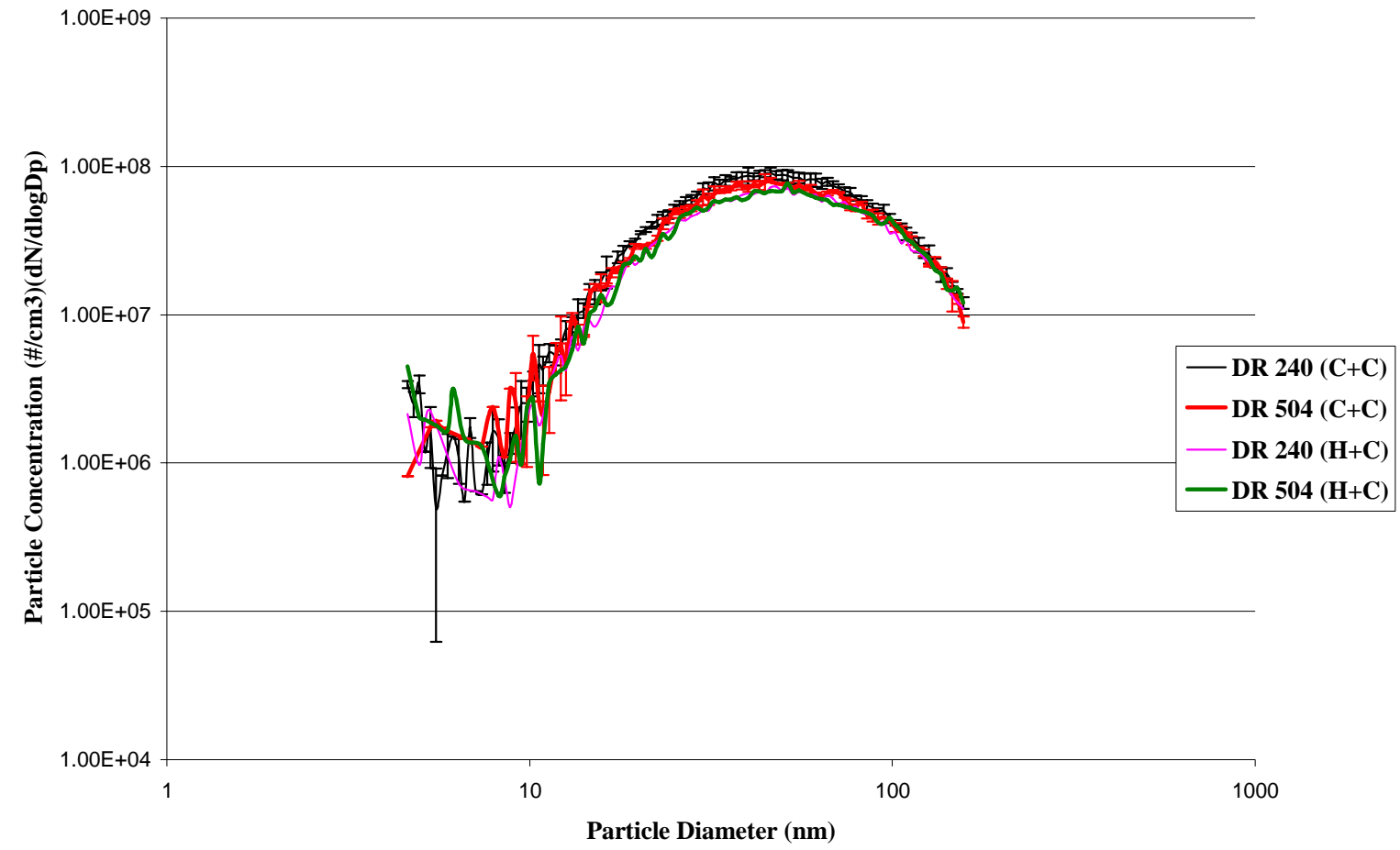

Figure 4-12. Particle Size Distribution at R 100 engine set point, Cold Dilution Method, DR 240 Vs DR 504

\subsection{Influence of Oxidation Catalyst}

An aftertreatment device (oxidation catalyst) was fitted to the engine exhaust and SMPS measurements were made before (BOC) and after the oxidation catalyst (AOC) to study the influence of the catalyst on the particle size measurements and concentrations. Data reported below are for dilution ratios 240 and 504 and both dilution methods for the engine operating points laid out in Table 4-1. 


\subsubsection{Dilution Ratio 240}

Figure 4-13 shows the particle size distributions before and after the oxidation catalyst for a dilution ratio of 240 for both the dilution methods. The engine was operated at I 50 mode.

As can be seen from the data shown, for both the dilution methods there is no change in the size distribution, but there is a drop in the total concentration of particles. CMD for the cold dilution method before the catalyst was $46.1 \mathrm{~nm}$ with a concentration of $8.7 \times 10^{7} \mathrm{\#} / \mathrm{cm}^{3}$, but the concentration dropped to $5.08 \times 10^{7} \# / \mathrm{cm}^{3}$ after the catalyst. The difference in concentration of particles before and after the catalyst for the hot dilution method is lesser when compared to the cold dilution method, but this can be attributed to the influence of dilution temperature on the particle growth. The reduction in concentration was noticed in the nuclei and accumulation mode indicating oxidation of particles in the oxidation catalyst. 


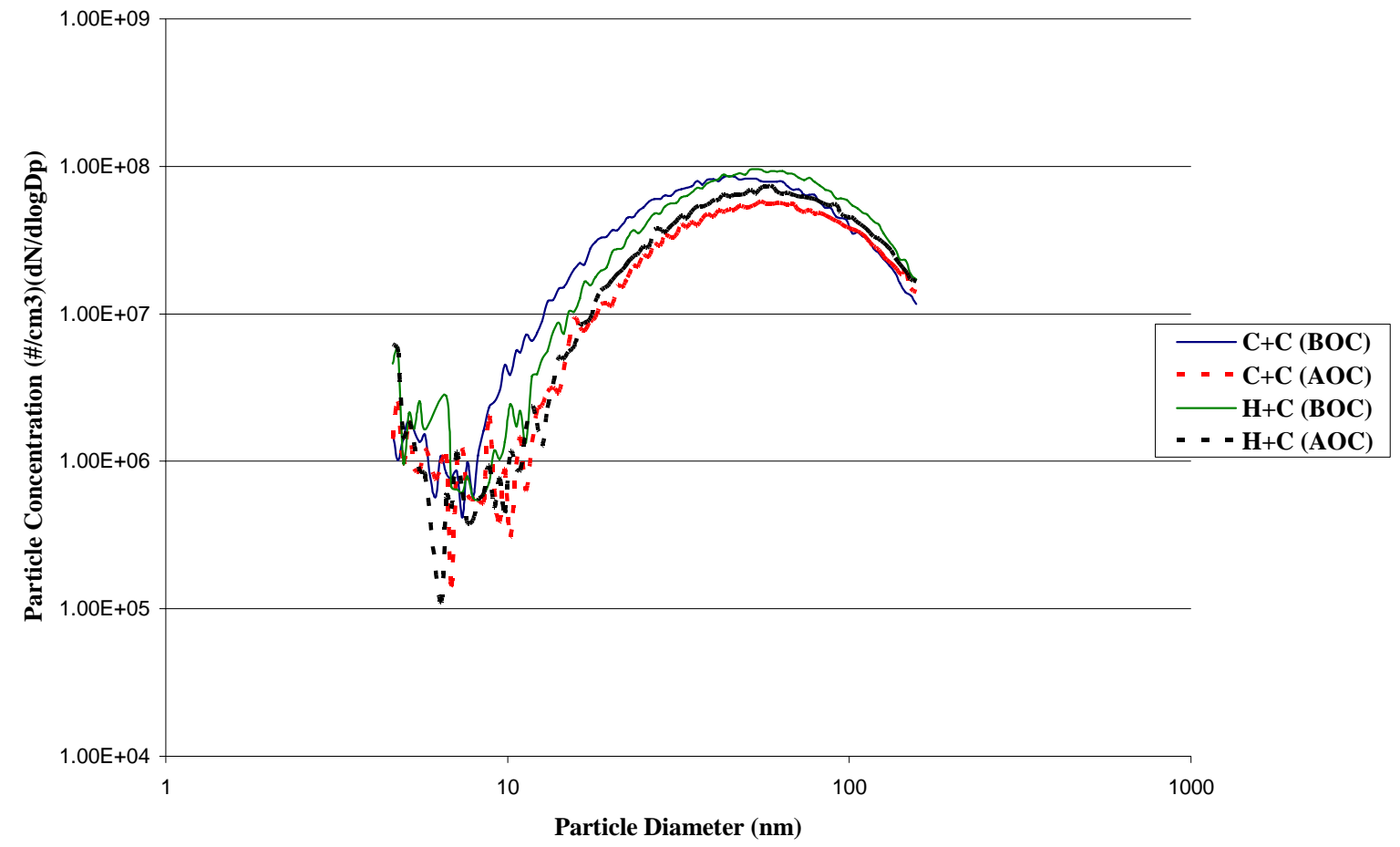

Figure 4-13. Particle Size Distribution at I 50 engine set point, Cold \& Hot Dilution Method, DR 240, before and after Oxidation Catalyst

Figure 4-14, 4-15 and 4-16 gives a comparison of SMPS data for the engine operating at I 100, R 50 and R 100 modes respectively for both dilution methods at a constant dilution ratio of 240 . 


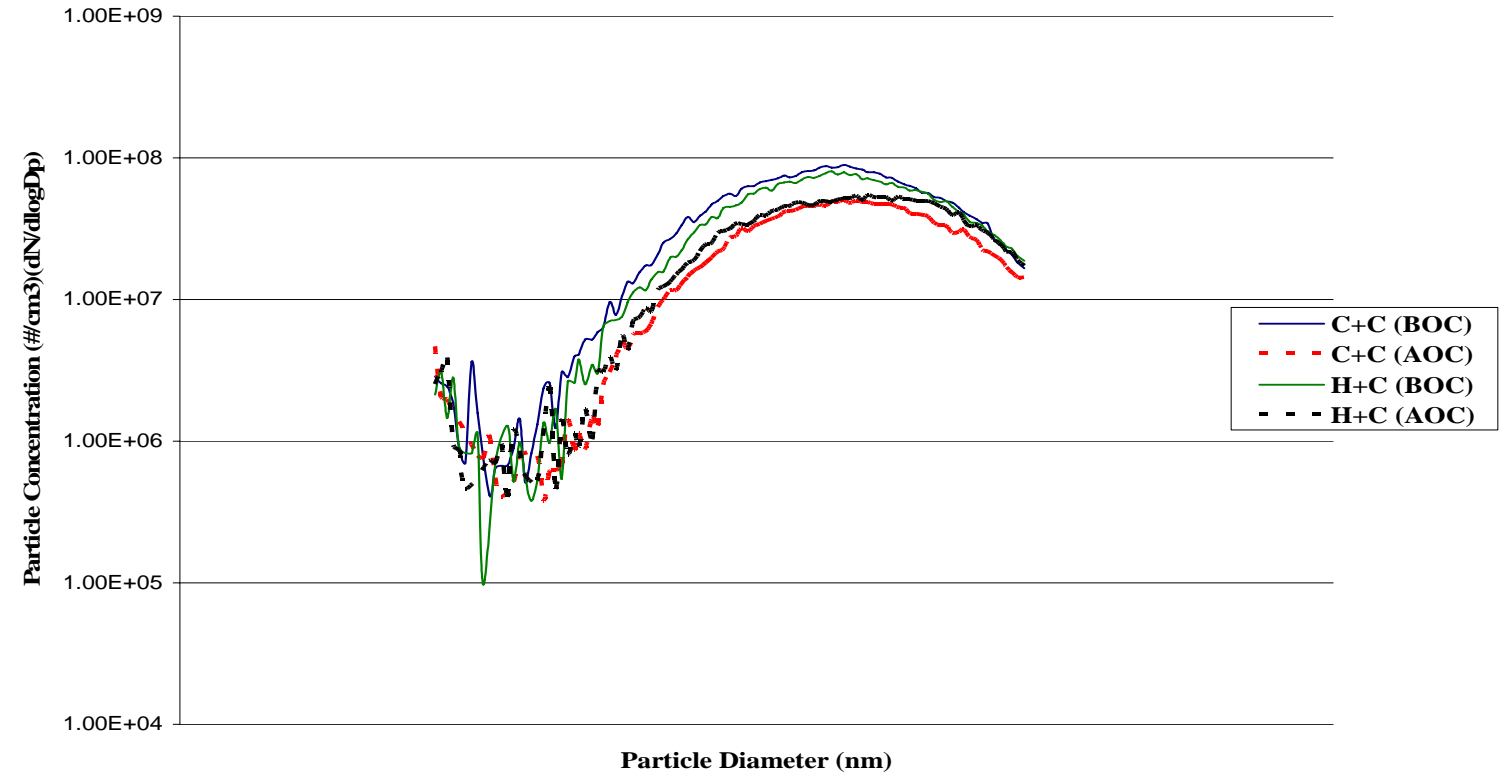

Figure 4-14. Particle Size Distribution at I 100 engine set point, Cold \& Hot Dilution Method, DR 240, Before and After Oxidation Catalyst

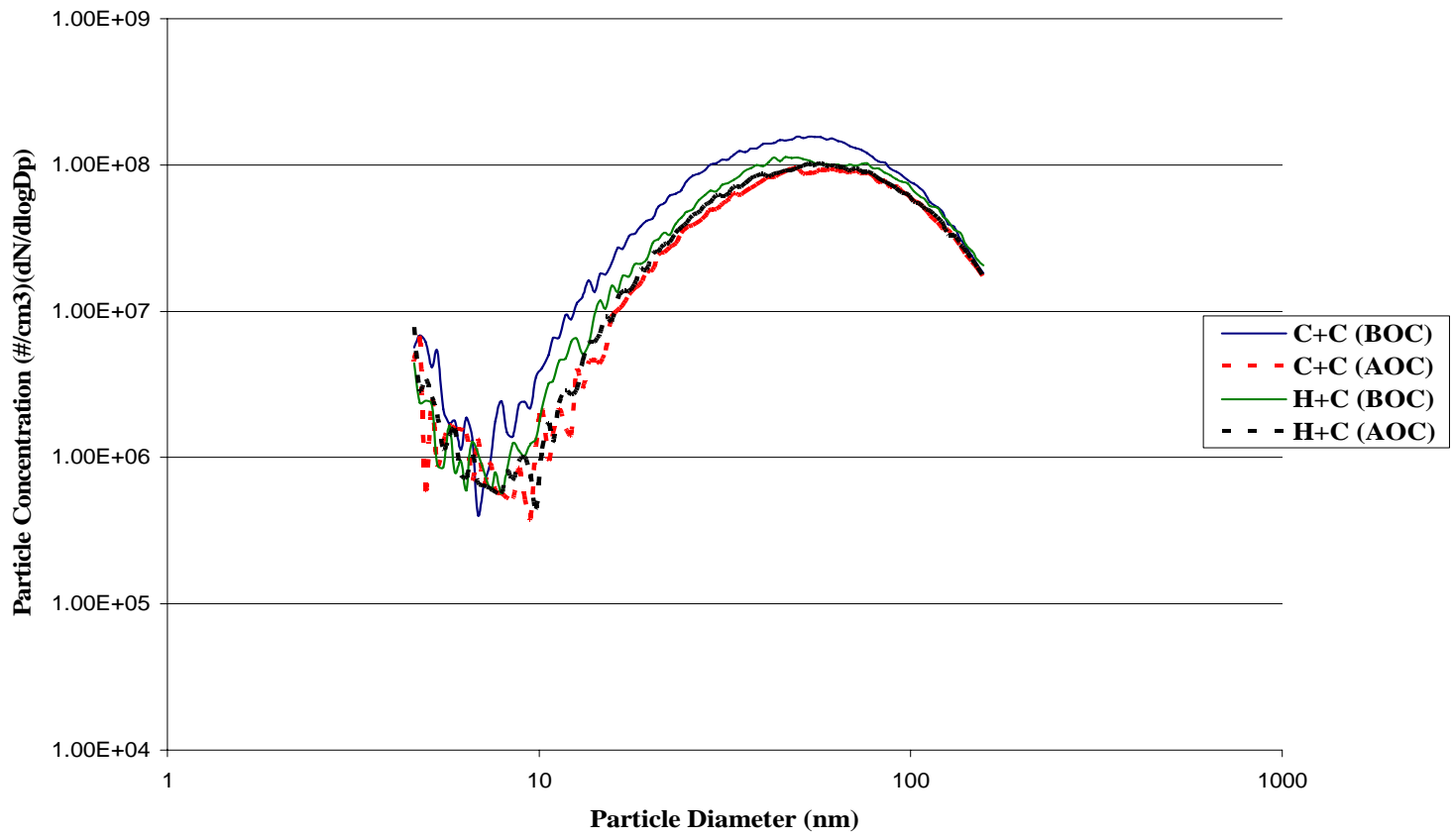

Figure 4-15. Particle Size Distribution at R 50 engine set point, Cold \& Hot Dilution Method, DR 240, Before and After Oxidation Catalyst 


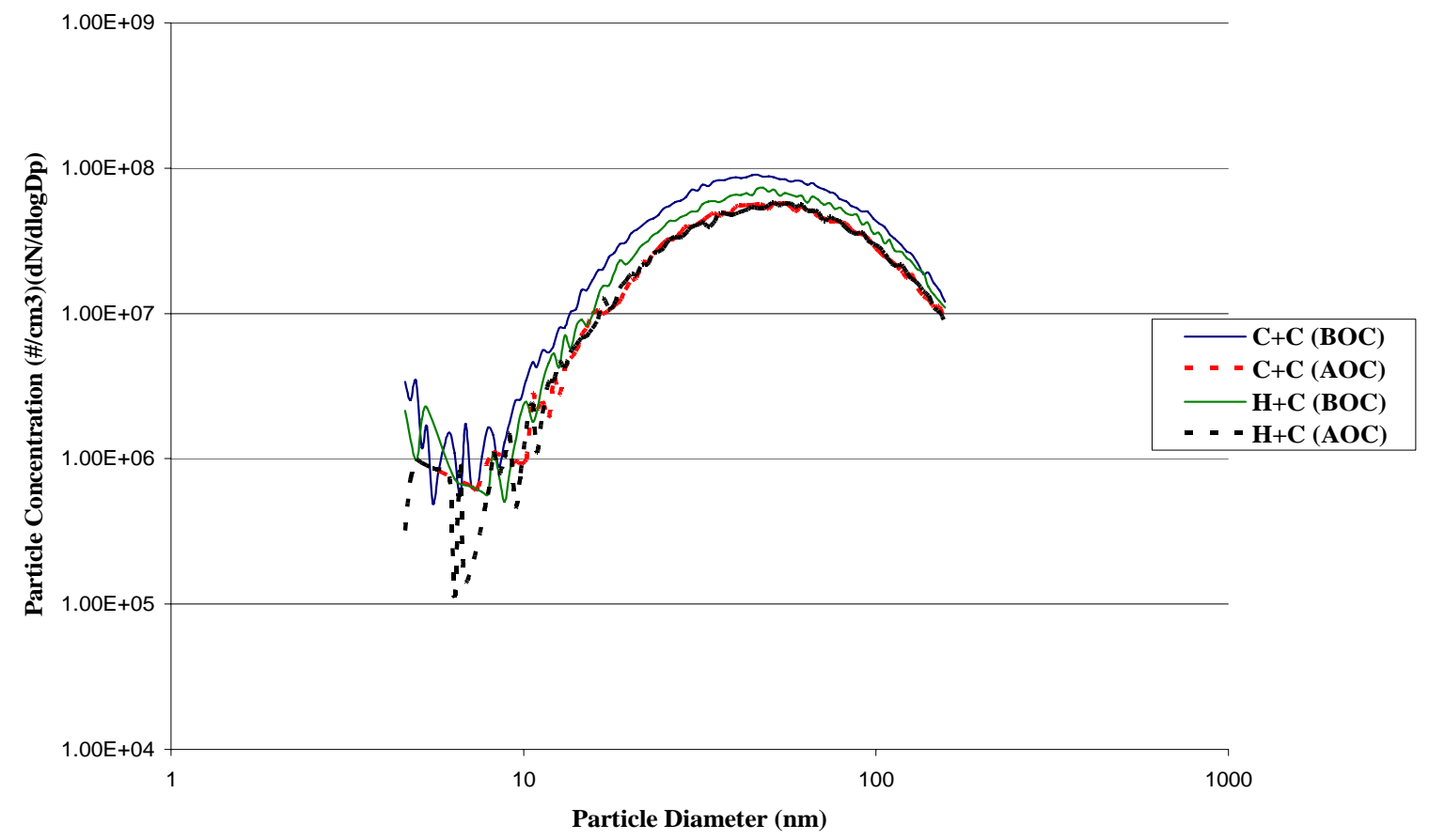

Figure 4-16. Particle Size Distribution at R 100 engine set point, Cold \& Hot Dilution Method, DR 240, Before and After Oxidation Catalyst

Results represented in Figures 4-14, 4-15 and 4-16 are similar to the results shown in Figure 4-13. Irrespective of the operating engine point, a drop in concentration of particles is noticed although the size distribution remains the same. Again the accumulation and nuclei mode particle concentration after the catalyst is reduced indicating oxidation of particles in the oxidation catalyst.

\subsubsection{Dilution Ratio 504}

SMPS data measured before and after the oxidation catalyst for a dilution ratio of 504 are discussed in this section. 


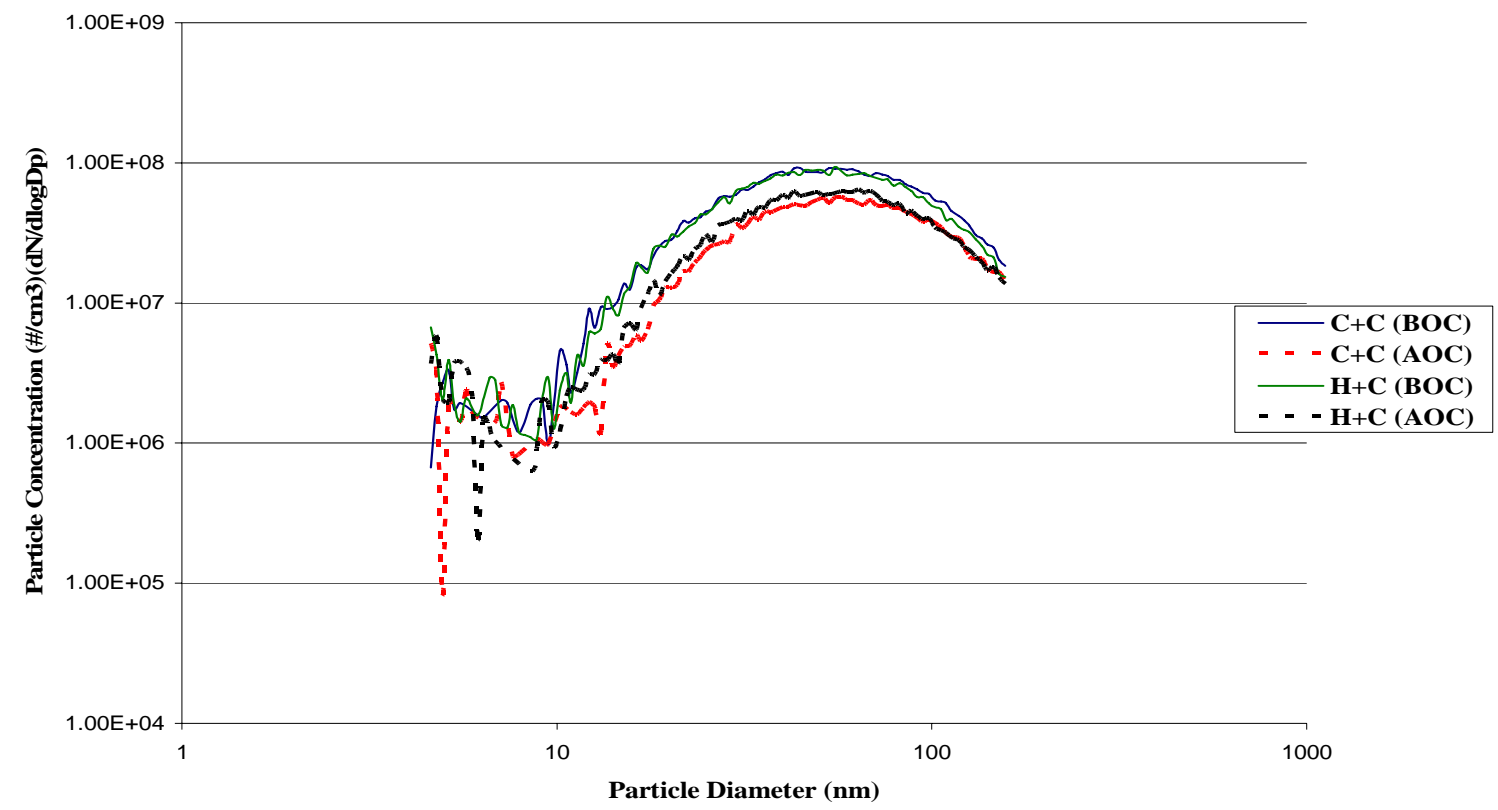

Figure 4-17. Particle Size Distribution at I 50 engine set point, Cold \& Hot Dilution Method, DR 504, Before and After Oxidation Catalyst

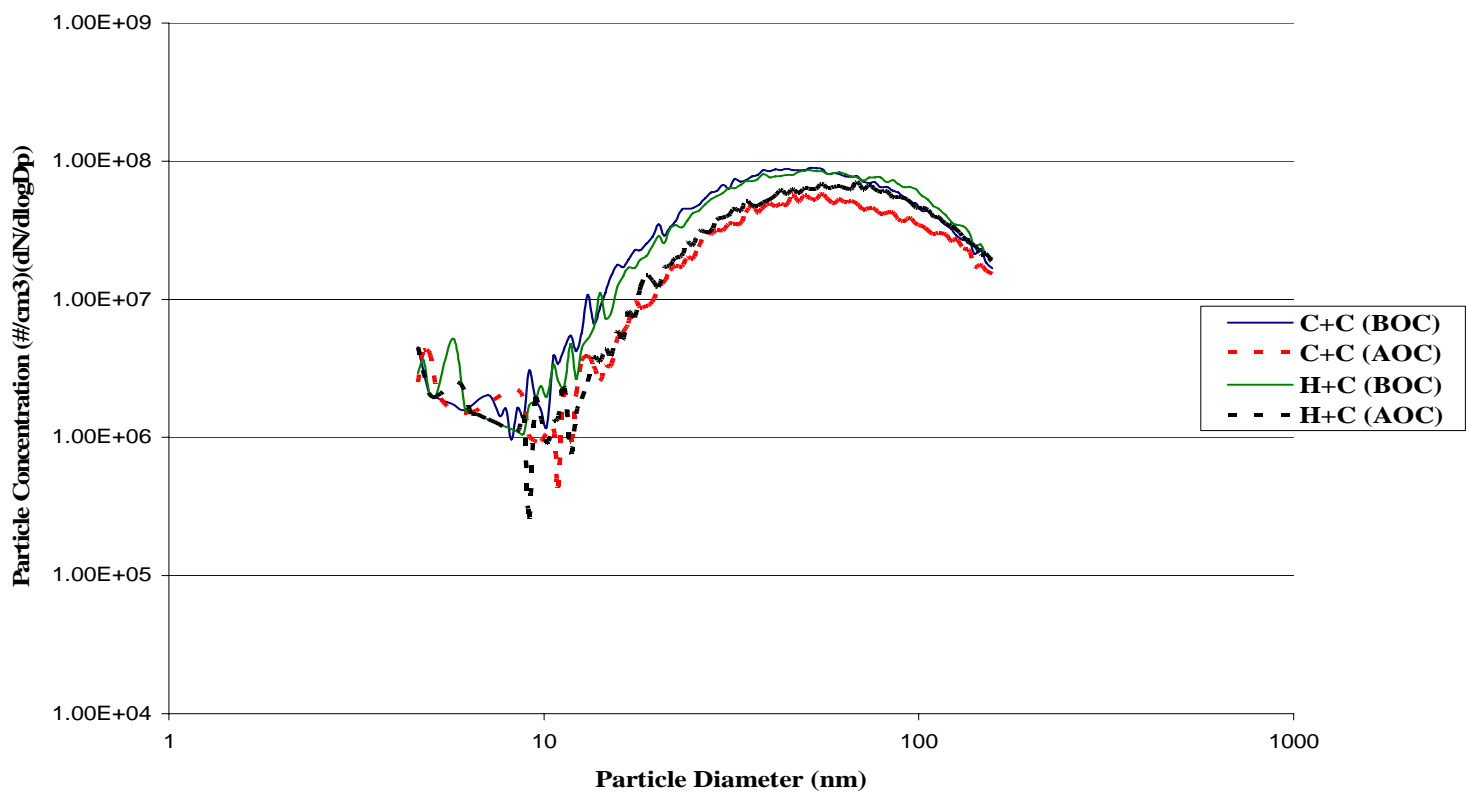

Figure 4-18. Particle Size Distribution at I 100 engine set point, Cold \& Hot Dilution Method, DR 504, Before and After Oxidation Catalyst 


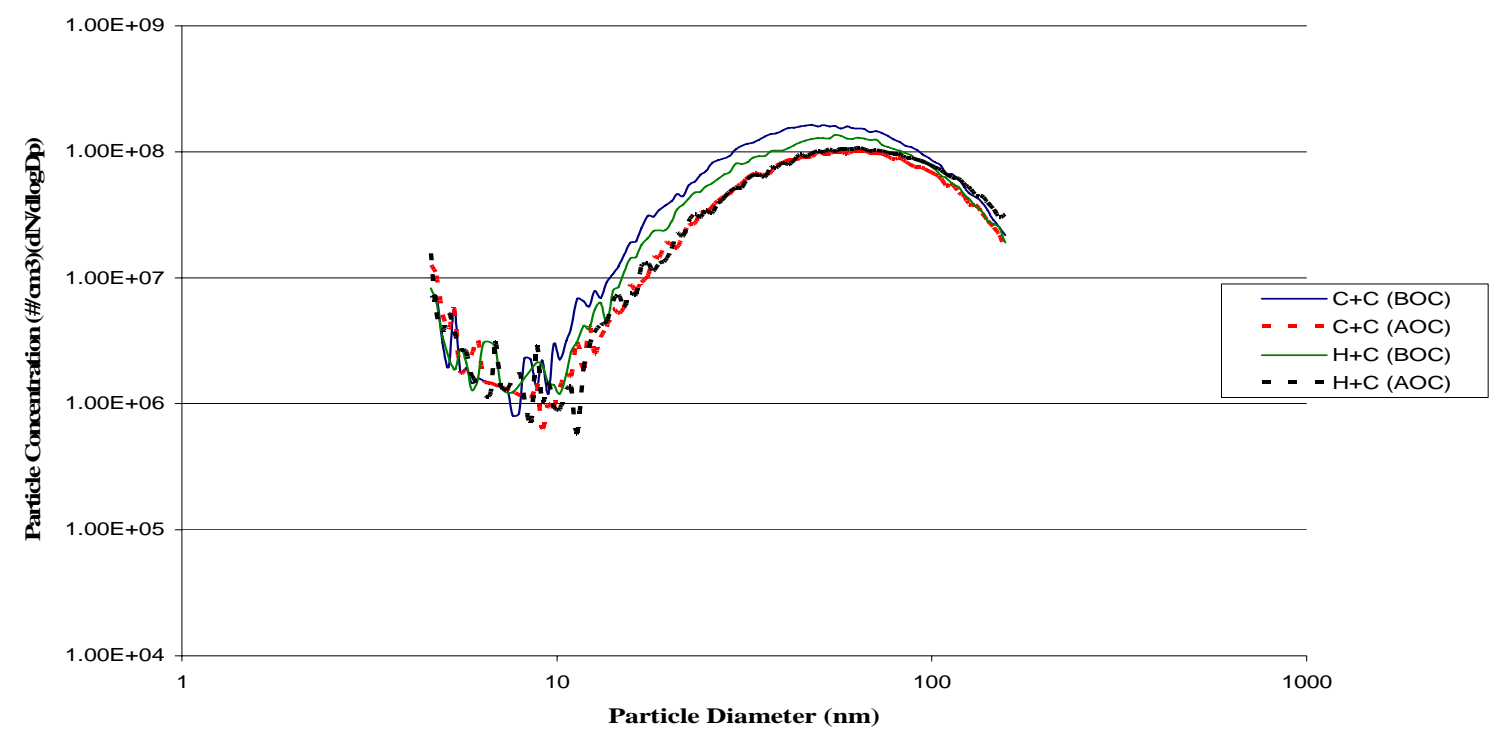

Figure 4-19. Particle Size Distribution at R 50 engine set point, Cold \& Hot Dilution Method, DR 504, Before and After Oxidation Catalyst

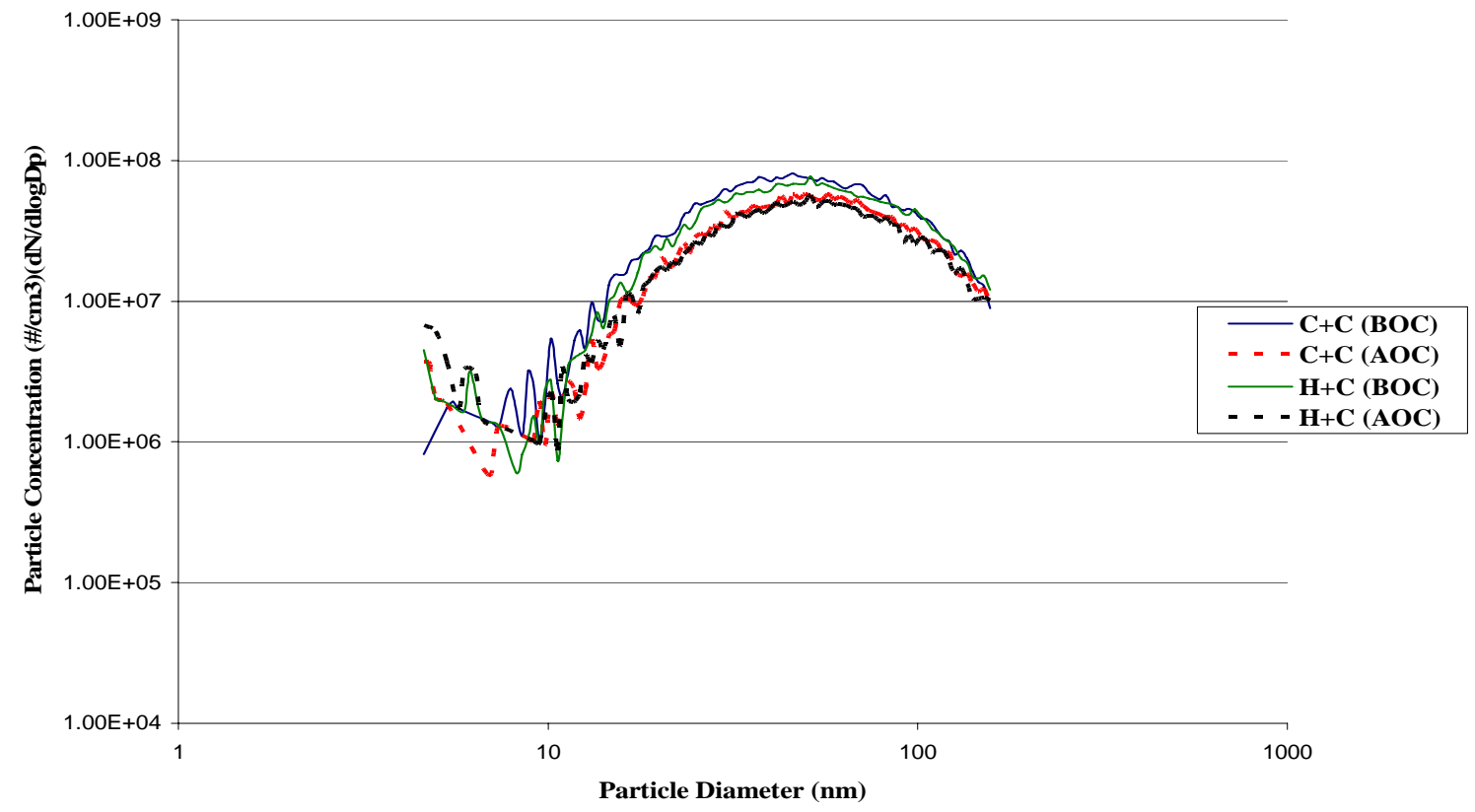

Figure 4-20. Particle Size Distribution at R 100 engine set point, Cold \& Hot Dilution Method, DR 504, Before and After Oxidation Catalyst 
Figures 4-17 to 4-20 represent SMPS particle size distributions and concentrations for engine operating points I 50, I 100, R 50 and R 100 respectively. Influence of the oxidation catalyst is similar to that observed for a dilution ratio for 240 . There is no change in the size distribution although a drop in concentration of particles after the oxidation catalyst for both the dilution methods is observed. 


\section{CONCLUSIONS AND RECOMMENDATIONS}

\subsection{Conclusions}

A two stage ejector based mini-dilution system was used to dilute the raw diesel exhaust and a 2005 model Daihatsu engine was used as the source. The Scanning Mobility Particle Sizer (SMPS 3936) was used to measure particle size distributions and concentrations. The observed results discussed in the previous chapter have given enough evidence to base the conclusions drawn below.

1) The influence of dilution method, hot air dilution and cold air dilution, although not pronounced at the high dilution ratios chosen, certainly is a factor in the measurement of PM size distributions and concentrations. Results obtained from the data obtained for hot air dilution method and compared with the data from cold air dilution method, show that the influence of the volatile fraction on the PM size distribution is reduced in the case of the former. The hot dilution method could be used as an alternative to thermodesorbers if the intention is to eliminate the effect of volatile fraction on the measurements made.

2) The dilution ratios chosen for this study, namely 240 and 504, did not significantly affect the distribution or concentrations. Results of this study are in agreement with prior studies. It may be concluded that accumulation mode particles are not affected by high dilution ratios. Nucleation mode particles might be affected at lower dilution ratios but can be eliminated by using hot air to dilute the raw exhaust.

3) SMPS measurements made after the oxidation catalyst indicated a decrease in concentration of particles in the accumulation mode and the nuclei mode. Prior studies have indicated that removal of the carbonaceous or solid particles enhances the chances of formation of nucleation mode particles but this was not observed from the results obtained in 
this study. It can be safely concluded that the reason for the decrease in concentration is due to oxidation of PM in the oxidation catalyst.

\subsection{Recommendations}

1. A thermodesorber should be used in the same setup to evaluate both the methods available currently to eliminate the influence of the volatile fraction on the PM size distribution and concentration.

2. DOC's of different coating materials should be compared to study the oxidizing effect of these materials. 


\section{REFERENCES}

1. Bagley, S.T., Baumgard, K.J., Gratz, L.D., Johnson, J.H., and Leddy, D.G., 1996. "Characterization of Fuel and Aftertreatment Device Effects on Diesel Emissions." Research Report No.76. Health Effects Institute. September 1996.

2. Scheer, V., Krichner, U., Casati, R., Vogt, R., Wehner, B., Philippin, S., Wiedensohler, A., Hock, N., Schneider, J., Weimer, S., and Borrman, S., "Composition of Semi-volatile Particles from Diesel Exhaust," SAE Technical Paper No. 2005-01-0197, 2005.

3. Kittelson, D.B., "Engines and Nanoparticles: A Review", Journal of Aerosol Science, Vol. 29, No. 5/6, pp.575-588, 1998.

4. Kittelson, D.B., Watts, W. F. and Arnold, M., "Review of Diesel Particulate Matter Sampling Methods, Supplemental Report \# 2, Aerosol Dynamics, Laboratory and On Road Studies", University of Minnesota, 1998.

5. Morrow, P. E., Bates, D. V., Fisher, B. R., et al., "Deposition and Retention Models for Internal Dosimetry of the Human Respiratory Tract (Report of the International Commission on Radiological Protection: ICRP: Task Group on Lung Dynamics)", Health Phys. 12, pp. 173-207, 1964.

6. Rape, O. G., "Deposition and Clearance of Inhaled Aerosols", MECHANISM IN RESPIRATORY TOXICOLOGY, Vol. 1, pp. 27-96. H. Wits Chi and P. Nettesheim, Eds. CRC Press, Boca Raton, Florida, 1982.

7. Dockery, D. W., and Pope, C. A., Annual Review of Public Health 15, pp. 107-132, 1994.

8. Pope, C. A., Burnett, R. T., Thurston, G. D., Thun, M. J., Calle, E. E., Krewski, D., and Godleski, J. J., "Cardiovascular Mortality and Long-term Exposure to Particulate Air Pollution: Epidemiological Evidence of General Pathophysiological Pathways of Disease, Circulation”, 109, pp. 71-77, 2004.

9. Donaldson, K., Li, X. Y., and MacNee, W., Ultrafine (Nanometer) Particle Mediated Lung Injury, Journal of Aerosol Science, Vol 29, pp. 553-560, 1998. 
10. Suresh, A., and Johnson, J. H., "A Study of the Dilution Effects on Particle Size Measurement from a Heavy-Duty Diesel Engine with EGR," SAE Technical Paper No. 2001-01-0220, 2001.

11. Pagan, J., "Study of Particle Size Distributions Emitted by a Diesel Engine," SAE Technical Paper No. 1999-01-1141, 1999.

12. Kittelson, D. B., and Abdul-Khalek, I., "Nanoparticle Formation During Exhaust Dilution." $2^{\text {nd }}$ ETH Workshop on Nanoparticle Measreument, Zurich, 7 August 1998.

13. Wei, Q., Kittelson, D.B., and Watts, W. F., "Single-Stage Dilution Tunnel Performance," SAE Technical Paper No. 2001-01-0201, 2001.

14. Abdul-Khalek, I. S., Kittelson, D. B., and Brear, F., "The Influence of the Dilution Conditions on Diesel Exhaust Particle Size Distribution Measurements," SAE Technical Paper No. 1999-01-1142, 1999.

15. Burtscher, H., Baltensperger, U., Bukowiecki, N., Cohn, P., Huglin, C., Mohr, M., Nyeki, S., Schmatloch, V., Streit, N., and Weingartner, E., "Separation of volatile and nonvolatile aerosol fractions by thermodesorption: instrumental development and applications,” Journal of Aerosol Science Vol.32, pp 427-442, 2001.

16. Abdul-Khalek, I. S., and Kittelson, D. B., "Real Time Measurement of Volatile and Solid Exhaust Particles Using a Catalytic Stripper,” SAE Technical Paper No. 950236, 1995.

17. Coutant, R. W., Callahan, P. J., and Kuhlman, M. R., "Design and Performance of a HighVolume Compound Annular Denuder,’ Journal of Atmospheric Environment, Vol. 23, pp 2205-2211, 1989.

18. Fierz, M., and Burtscher, H., "Separation of solid and volatile fraction by thermodesorption and hot dilution," PMP report CH6.

19. Kawai, T., Goto, Y., and Odaka, M., "Influence of Dilution Process on Engine Exhaust Nano-particles," SAE Technical Paper No. 2004-01-0963, 2004.

20. Hunter, G., Scholl, J., Hibbler, F., Bagley, S., Leddy, D., Abata, D., and Johnson, J., “The Effects of Fuels on Diesel Oxidation Catalyst Performance and the Physical, Chemical, 
and Biological Character of Diesel Particulate Emissions," SAE Technical Paper No. $811192,1981$.

21. Warner, J. R., Huynh, C., Janakiraman, G., Johnson, J. H., and Bagley, S. T., “Oxidation Catalytic Converter and Emulsified Fuel Effects on Heavy-Duty Diesel Engine Particulate Matter Emissions,” SAE Technical Paper No. 2002-01-1278, 2002.

22. Baumgard, K. J., and Johnson, J. H., “The Effect of Fuel and Engine Design on Diesel Exhaust Particle Size Distributions,” SAE Technical Paper No. 960131, 1996.

23. Air-Vac Engineering, http://www.air-vac-eng.com/PDF\%20Files/td.pdf, October 5, 2006.

24. TSI Incorporated, http://www.tsiinc.de/documents/1933796k-3936.pdf, October 5, 2006.

25. TSI Incorporated, http://www.tsi.com/documents/1933793d-3480.pdf, October 5, 2006.

26. TSI Incorporated, http://www.tsi.com/documents/1933792g-3080.pdf, October 5, 2006.

27. TSI Incorporated, http://www.tsiinc.fr/documents/1933762i-3025A.pdf, February 14, 2007. 


\section{APPENDIX A}

\section{Scanning Mobility Particle Sizer (SMPS), Model 3936 Specifications}

\section{SMPS Spcoilizatione}

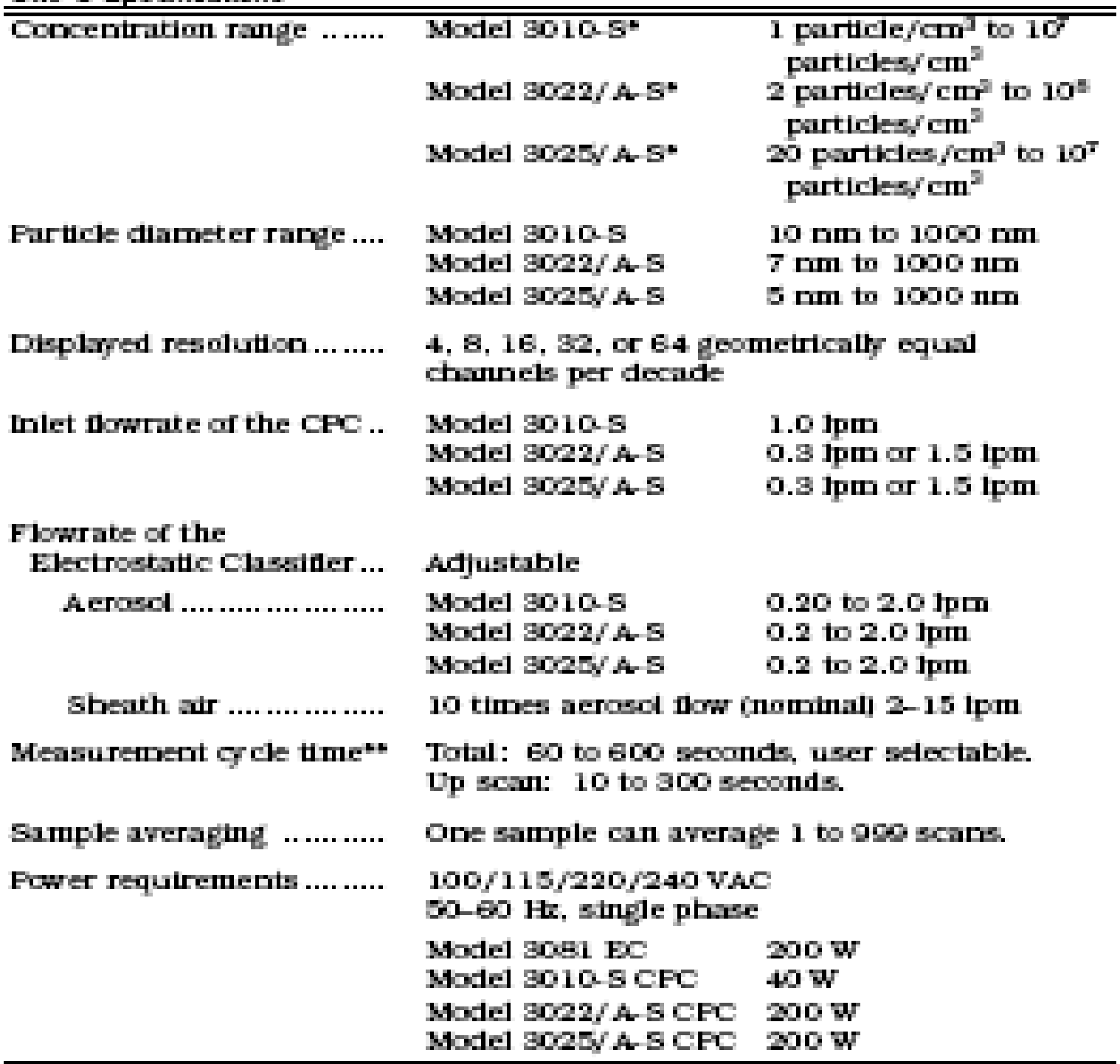

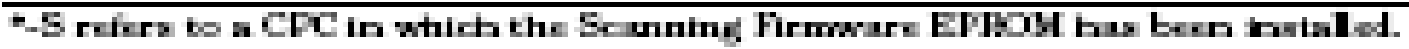

- Hetual measurament times defend an partide enceniratin, selweted stas

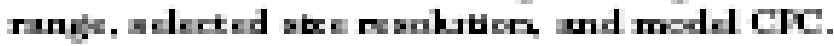




\section{APPENDIX B}

\section{Model 3025 A Ultrafine Condensation Particle Counter Specifications}

Mode 2025A Gpe:/fratons

Minimum particle steo

30 deleticn at 3 nm

$97 \mathrm{x}$ deletion at $5 \mathrm{~nm}$

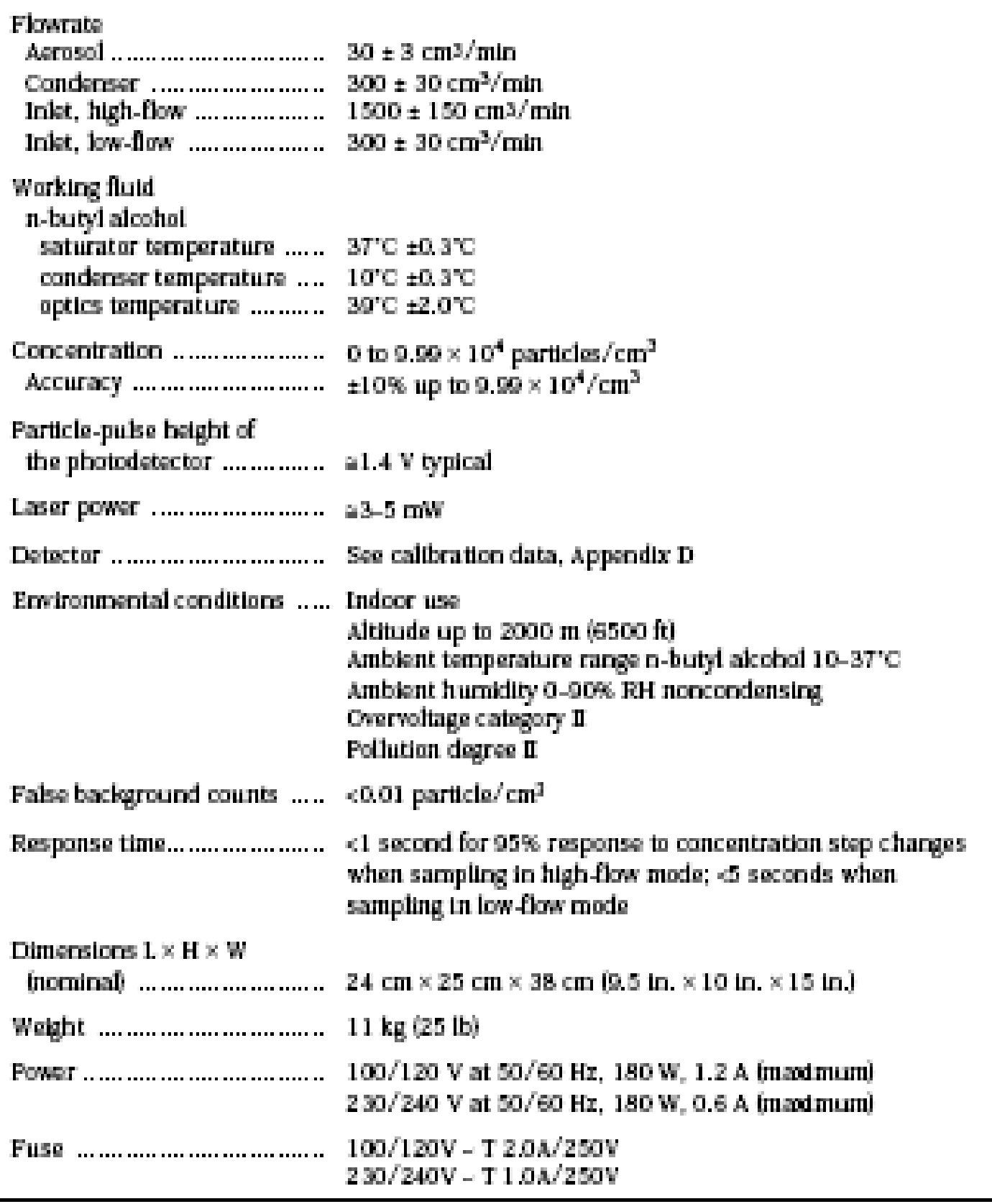




\section{MathCAD Reduction Program for SMPS Data}

\section{Input Dilution Ratio}

DR $:=4 C$

Select Raw data File

$$
\begin{aligned}
& :=\text { 酐 } \\
& \text { C.1.1.1150-Stage 1-DR 40 Hot-S5.tXt }
\end{aligned}
$$

Rowsize := rows $($ Raw $)$

$\mathbf{N}:=$ Rowsize $-2 \epsilon$

Raw1 := submatrix $($ Raw, 1, N , 1, 2)

Rawcount: $=$ Raw1 $^{\langle 2\rangle}$

Size $:=\operatorname{Raw1} 1^{\langle 1\rangle}$

C := Rawcount DR

Reduced := augment(Size , C)

Select output reduced data file

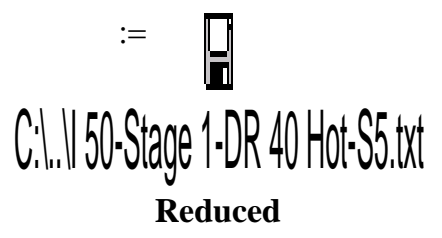

